\title{
Large eddy simulation of turbulent diffusion jet flames based on novel modifications of flamelet generated manifolds
}

\section{Citation for published version (APA):}

Zadsirjan, S., Tabejamaat, S., Abtahizadeh, E., \& van Oijen, J. (2020). Large eddy simulation of turbulent diffusion jet flames based on novel modifications of flamelet generated manifolds. Combustion and Flame, 216, 398-411. https://doi.org/10.1016/j.combustflame.2020.02.018

\section{Document license:}

TAVERNE

DOI:

10.1016/j.combustflame.2020.02.018

Document status and date:

Published: 01/06/2020

\section{Document Version:}

Publisher's PDF, also known as Version of Record (includes final page, issue and volume numbers)

\section{Please check the document version of this publication:}

- A submitted manuscript is the version of the article upon submission and before peer-review. There can be important differences between the submitted version and the official published version of record. People interested in the research are advised to contact the author for the final version of the publication, or visit the $\mathrm{DOI}$ to the publisher's website.

- The final author version and the galley proof are versions of the publication after peer review.

- The final published version features the final layout of the paper including the volume, issue and page numbers.

Link to publication

\section{General rights}

Copyright and moral rights for the publications made accessible in the public portal are retained by the authors and/or other copyright owners and it is a condition of accessing publications that users recognise and abide by the legal requirements associated with these rights.

- Users may download and print one copy of any publication from the public portal for the purpose of private study or research.

- You may not further distribute the material or use it for any profit-making activity or commercial gain

- You may freely distribute the URL identifying the publication in the public portal.

If the publication is distributed under the terms of Article 25fa of the Dutch Copyright Act, indicated by the "Taverne" license above, please follow below link for the End User Agreement:

www.tue.nl/taverne

Take down policy

If you believe that this document breaches copyright please contact us at:

openaccess@tue.nl

providing details and we will investigate your claim. 


\title{
Large eddy simulation of turbulent diffusion jet flames based on novel modifications of flamelet generated manifolds
}

\author{
Saeedreza Zadsirjan ${ }^{\mathrm{a}}$, Sadegh Tabejamaat ${ }^{\mathrm{a}, *}$, Ebrahim Abtahizadeh ${ }^{\mathrm{b}}$, Jeroen van Oijen ${ }^{\mathrm{b}}$ \\ a Department of Aerospace Engineering, Amirkabir University of Technology, Iran \\ ${ }^{\mathrm{b}}$ Department of Mechanical Engineering, Eindhoven University of Technology, the Netherlands
}

\section{A R T I C L E I N F O}

\section{Article history:}

Received 11 September 2018

Revised 13 February 2020

Accepted 14 February 2020

\section{Keywords:}

Flamelet generated manifold

Progress variable

Look-up table

Large eddy simulation

Turbulent diffusion flame

Lifted flame

\begin{abstract}
A B S T R A C T
A novel mathematical definition is introduced to achieve the inherently monotonic progress, namely $\mathrm{Ab}$ solute Cumulative Variation (ACV). The classical progress variable is defined as a weighted summation of species mass fraction while weight factors are determined in the ad-hoc procedure. The ACV definition presents the systematic method to generate a fully bijective look-up table appropriate for the vast combustion applications. This method utilizing the preferential diffusion effects and has the potential to predict the autoignition delay time as well as pollutants, like $Y_{\mathrm{CO}}$ and $Y_{\mathrm{NO}}$. The flamelet-generated manifold is coupled with ACV to make the ACV-FGM method. Furthermore, the Variable Ignition Mixing Layer (VIML) is presented as a modified method to generate a 2-D look-up table for the multi-inflow streams as well as varying composition reactants at the domain boundaries. This model helps to reduce the size of the look-up table for complex inflow boundary conditions and computational cost as well. The validation process for the ACV-FGM and VIML methods includes a one-dimensional laminar flame along with large eddy simulation (LES) of the Sandia piloted flames D, E, and F, and Delft Jet-Hot Coflow (DJHC) burner as lifted turbulent jet flame. The results indicate the ACV-FGM method successfully predicts the autoignition delay time, lift-off height, temperature rise as well as spices mass fractions and pollutants. Moreover, The VIML method appropriately reproduces the variation of chemical compositions and temperature at the domain boundary using the 2-D look-up table.
\end{abstract}

(c) 2020 The Combustion Institute. Published by Elsevier Inc. All rights reserved.

\section{Introduction}

Combustion simulations using detail kinetic mechanisms can comprise hundreds of chemical species through a significant number of reactions. Solving turbulent combustion requires prohibitive computational resources to achieve more accurate features to answer raising questions on the combustion process, and its application. This challenge motivates numerous efforts of combustion modeling to reduce computational cost while retaining the accuracy within an acceptable margin. Maas and Pope [1] introduced the intrinsic low-dimensional manifold (ILDM) that is founded on robust mathematical analysis of the chemical composition eigenvalue. This method automatically reduces the complex kinetic mechanisms to determine the low- dimensional manifold as a projection of high dimensional thermochemical space. However, this method is a treatment of the chemical term and it does not include the effects of convection and diffusion terms, conse-

\footnotetext{
* Corresponding author at: Professor at Department of Aerospace Engineering, Amirkabir University of Technology, Tehran, Iran.

E-mail address: sadegh@aut.ac.ir (S. Tabejamaat).
}

quently, ILDM is not appropriate for applications such as the lowtemperature ignition [2].

The flamelet look-up table is a way to overcome the limitations of the ILDM. The detailed solution of the 1-D laminar flame is tabulated using the independent variable to describe the thermochemical state. The flame prolongation of ILDM (FPI) [3], flamelet-generated manifolds (FGM) [4], and flamelet/progressvariable (FPV) model [5,6] are properly utilized the ILDM advantages along with the flamelet equation of Peters [7,8] and the progress variable concept [5] to tabulate the canonical 1-D laminar flamelet. The flamelet-family models successfully implemented to the laminar premixed $[9,10]$ and partially premixed and diffusion flames [11], as well as turbulent premixed [12], and nonpremixed [13-18] configurations. The preferential diffusion effect was taken into account in premixed [19] and non-premixed flames [19-23] and its impact on the autoignition of the turbulent jet [24] as well.

The tabulation procedure remains an open challenge for investigators to generate a more accurate look-up table while trying to keep the dimension and size of the table as low as possible to reduce the interpolation cost. The progress variable definition is key 
to produce a bijective look-up table. The progress variable, often defined based on the experience or ad hoc procedure [25]; therefore it results in a weak mathematical foundation [26]. The classical progress variable defined as a weighted summation of chemical species like $\mathrm{CO}, \mathrm{CO}_{2}$, and $\mathrm{H}_{2} \mathrm{O}$. This definition is not general for instance, the heavy hydrocarbon fuels decomposed to the lighter carbon compound with negligible heat release [15]. The accurate progress variable produces the bijective projection of time-state into the lower-dimensional manifold. Ihme et al. [25] proposed several rules to build the proper progress variable.

(a) The transport equation of the progress variable can be solved in reactive systems.

(b) The reactive scalar and the progress variable should be comparable to the time scales.

(c) The manifold should be constructed of the independent dimension.

(d) A point in the manifold should be determined a unique thermochemical state.

Najafi-Yazdi et al. [2] used a Principal Component Analysis (PCA)- also known as Proper Orthogonal Decomposition (POD)- to find the species weight factors of progress variable. PCA method is a standard procedure to reduce the order of phenomena to the low-dimension. Nonetheless, the PCA method obscures the physics of the problem and does not contain the manifold information while this problem intrinsically includes significant nonlinearities. Moreover, this method is formulated based on the unity Lewis number that adversely affects the generality of the method where preferential diffusion is playing an important role for example, in a hydrogen blended fuel [24].

Niu et al. [27] proposed the automated approach finding the weight function of all the chemical species mass fraction to define the progress variable based on the optimization algorithm. Two constraints were implemented on the progress variable as an objective of optimization: first, continues evolution of progress variable from unburnt to burn composition in a manner that it is bijective to time-state composition. Second, prevent a high rate of change of species in progress variable space to control numerical errors.

Göktolga et al. [28] presented the Multi-Stage FGM (MuSt-FGM) method to construct the FGM look-up table utilizing the Ignition Mixing Layer (IML) which was introduced by Abtahizadeh et al. [24] considering the preferential diffusion effect on autoignition phenomena. The Multi-Stage FGM method is an effort to generate a monotonic progress variable focusing on the pre-ignition progress of species mass fraction.

Briefly, the flamelet method is still struggling with two challenges. First, despite all the effort on progress variable definition, based on the authors' knowledge, none of the methods are mathematically proofed to build the fully monotonic progress variable to generate a bijective look-up table. Second, the accuracy and size of the look-up table are challenging for a higher dimension table. it is common practice to generate the look-up table with more than two dimensions for a multi-inflow stream or variable composition reactants, i.e., Sandia piloted flame [29] and Delft in Hot Coflow Burner [30,31].

In this paper, the Absolute Cumulative Variation (ACV-FGM) is introduced to build an inherently monotonic progress variable considering the preferential diffusion effects. Furthermore, The Variable Ignition Mixing Layer (VIML) method is developed based on the IML [24] to generate the two-dimensional FGM look-up table for the multi-inflow streams or variable composition reactant at the boundary condition of the fluid domain.

This paper is arranged as follows. The mathematical definition of the ACV progress variable and its diffusion coefficient for the non-unity Lewis number is provided in Section 2. The description of the VIML method is presented in Section 3. The validation and comparison of the ACV-FGM versus weighted summation progress variable for 1-D laminar flame are provided in Section 4. The LES formulation and simulation results of the Sandia piloted flames D, $\mathrm{E}$, and $\mathrm{F}$ as well as DJHC burner presented in Section 5 to validate the 3-D results based on the developed models. Finally, conclusions are deduced and presented in Section 6.

\section{Numerical approaches}

\subsection{Absolute cumulative variation}

The classical description of mixture fraction $\zeta$ and progress variable $\eta$ is a linear summation of species mass fraction multiplied by weight factors, $\gamma=\sum_{i} \alpha_{i} Y_{i}$. Where $\gamma$ can be replaced by mixture fraction and progress variable with their $\alpha_{i}$. The species weight factors of mixture fraction obtained from Bilger's [32] formulation. It is normalized so that it is minimum for the oxidizer stream $(\zeta=0)$ and maximum for the fuel stream $(\zeta=1)$. The weight factors for the progress variable are determined to make the monotonic evolution of the progress variable to generate the bijective look-up table. An appropriate look-up table correctly predicts ignition delay time, temperature rise, and chemical species progress. The time rate of change of $Y_{i}$ for one-dimensional configuration is extracted from the mass transport equation for species $i$,

$\frac{\partial Y_{i}}{\partial t}=\frac{1}{\rho} \frac{\partial}{\partial x}\left(\frac{\lambda}{L e_{i} c_{p}} \frac{\partial Y_{i}}{\partial x}\right)-\frac{\partial\left(u Y_{i}\right)}{\partial x}+\omega_{i}$

$\frac{\partial Y_{i}}{\partial t}$ is a function of the chemical source term as well as convection and diffusion mass transfer. The chemical source terms are rarely negative for final combustion products such as $\mathrm{CO}_{2}$ and $\mathrm{H}_{2} \mathrm{O}$ through the whole reaction. However, the molecular diffusion along with the convection, which is induced by the density gradient of the reactive domain, can lead to negative $\frac{\partial Y_{i}}{\partial t}$ even for $\mathrm{H}_{2} \mathrm{O}$ for the noticeable duration, i.e. pre-ignition. Because of the significant nonlinearities behavior of $Y_{i}$, the weight factor determination for species $i$ is a time-consuming ad-hoc procedure. In some cases, it has no particular mathematical solution to obtain a fully monotonic progress variable, which comprises of linear summation of weighted species mass fraction. To overcome the difficulties, the Absolute Cumulative Variation (ACV) is introduced as a novel approach to define the inherently monotonic progress variable. In this method, the progress variable of species $i$ is defined as the derivative of the absolute rate of change of mass faction $i$.

$\eta_{i}=\int_{0}^{t}\left|\frac{d Y_{i}}{d t}\right| d t$

The progress variable is defined as a summation of $\eta_{i}, \eta=$ $\sum_{i=1}^{N s} c_{i} \eta_{i}$. The parameter $c_{i}$ is a weight factor to adjust the magnitude of species mass fraction to minimize numerical error through FGM look-up table interpolation.

Figure 1 shows the trend of mass fraction $\mathrm{HO}_{2}$ and $\eta_{\mathrm{HO}_{2}}$ at stoichiometric mixture fraction for the Laminar Jet in Hot Coflow (LJHC) which will be discussed in the following sections. $\mathrm{YHO}_{2}$ as an intermediate chemical species is produced and consumed in the reaction process while the $\eta_{\mathrm{HO}_{2}}$ is increasing and monotonic.

\subsection{Transport equation of progress variable}

The ACV progress variable is not a physical parameter; therefore its diffusion coefficient and chemical source term should be determined mathematically. These two parameters are calculated based on the comparison of the transport equation of $\eta_{i}$, and mass 


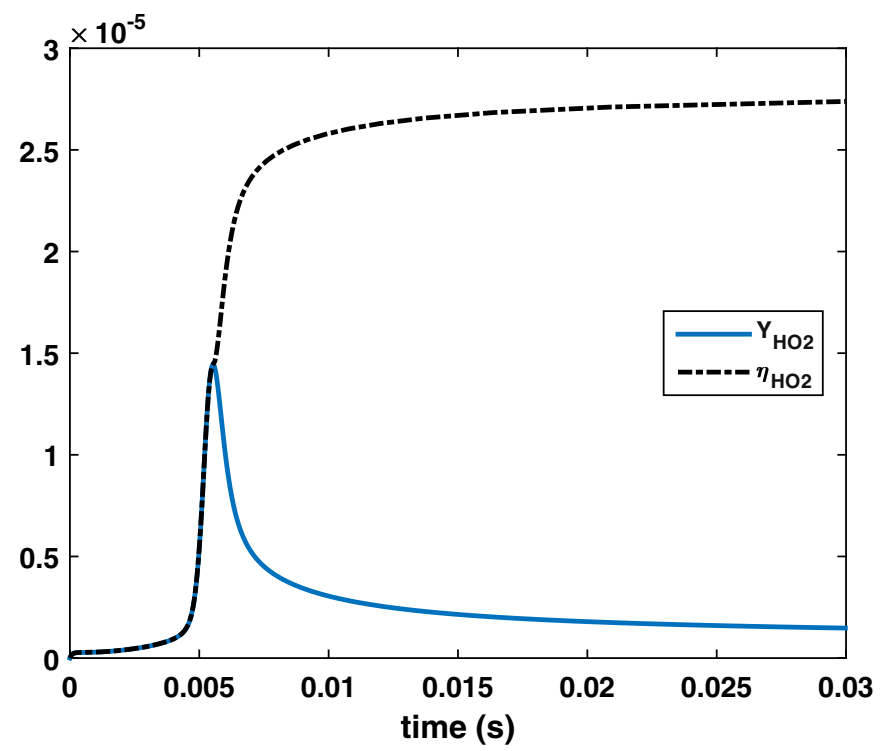

Fig. 1. Comparison of $\mathrm{YHO}_{2}$ and $\eta_{\mathrm{HO}_{2}}$ at stoichiometric mixture fraction for Laminar Jet in Hot Coflow (LJHC) [33,34]. The $\mathrm{Y}_{\mathrm{HO}_{2}}$ is produced and consumed in a chemical reaction while $\eta_{\mathrm{HO}_{2}}$ is increasing and monotonic.

fraction $Y_{i}$. The relation between these two equations is the definition of $\eta_{i}=\int\left|\frac{d Y_{i}}{d t}\right| d t$. The transport equations of $Y_{i}$ and $\eta_{i}$ are as follows

$\rho \frac{d Y_{i}}{d t}=-\rho u \nabla \cdot\left(Y_{i}\right)+\nabla \cdot\left(\rho D_{Y i} \nabla Y_{i}\right)+\omega_{i}$

$\rho \frac{d \eta_{i}}{d t}=-\rho u \nabla \cdot\left(\eta_{i}\right)+\nabla \cdot\left(\rho D_{\eta_{i}} \nabla \eta_{i}\right)+\omega_{\eta_{i}}$

From the mathematical definition of the absolute value of a quantity, $\left|\frac{d Y_{i}}{d t}\right|=\operatorname{sgn}\left(\frac{d Y_{i}}{d t}\right) \cdot \frac{d Y_{i}}{d t}$, where $\operatorname{sgn}$ is the sign function. For the sake of simplicity, $W_{i}$ is defined as

$W_{i}=\operatorname{sgn}\left(\frac{d Y_{i}}{d t}\right)$

The source term of $\eta_{i}$ is equal to

$\omega_{\eta_{i}}=W_{i} \omega_{i}$

As $\eta_{i}=\int\left|\frac{d Y_{i}}{d t}\right| d t$, the L.H.S of transport equation of $\eta_{i}$, Eq. (4), is equal to

$\rho \frac{d \eta_{i}}{d t}=\rho\left|\frac{d Y_{i}}{d t}\right|$

Using Eq. (6) to rewrite Eq. (7)

$\rho \frac{d \eta_{i}}{d t}=\rho W_{i} \frac{d Y_{i}}{d t}$

The RHS of both Eqs. (3) and (4) is equal when the transport equation of $Y_{i}$, Eq. (3), is multiplied by $W_{i}$.

$$
\begin{aligned}
& W_{i}\left(-\rho u \nabla \cdot\left(Y_{i}\right)+\nabla \cdot\left(\rho D_{Y i} \nabla Y_{i}\right)+\omega_{i}\right) \\
& =-\rho u \nabla \cdot\left(\eta_{i}\right)+\nabla \cdot\left(\rho D_{\eta_{i}} \nabla \eta_{i}\right)+\omega_{\eta_{i}}
\end{aligned}
$$

Replacing the source term of $\eta_{i}, \omega_{\eta_{i}}$, with $W_{i} \omega_{i}$, and rewrite the Eq. (9) yields

$\nabla \cdot\left(\rho D_{\eta_{i}} \nabla \eta_{i}\right)=\rho u\left(\nabla .\left(\eta_{i}\right)-W_{i} \nabla \cdot\left(Y_{i}\right)\right)+W_{i} \nabla \cdot\left(\rho D_{Y i} \nabla Y_{i}\right)$

For a 1D configuration, the spatial derivative is on the $x$ direction; therefore the Eq. (10) is rewritten as

$$
\frac{d}{d x}\left(\rho D_{\eta_{i}} \frac{d \eta_{i}}{d x}\right)=\rho u\left(\frac{d \eta_{i}}{d x}-W_{i} \frac{d Y_{i}}{d x}\right)+W_{i} \frac{d}{d x}\left(\rho D_{Y i} \frac{d Y_{i}}{d x}\right)
$$

To simplify the second term on the RHS of Eq. (11) assume that $W_{i}$ is independent of $x$ so it can be written as $\frac{d}{d x}\left(W_{i} \rho D_{Y i} \frac{d Y_{i}}{d x}\right)$. This assumption is based on the mathematical definition of $W_{i}$. The $\frac{d W_{i}}{d x}=\frac{d}{d x} \operatorname{sgn}\left(\frac{d Y_{i}}{d t}\right)$ whereas the derivative of Sign function is zero except at the point where $\frac{d Y_{i}}{d t}$ changes sign that is equal to Dirac delta function $\delta(x, t)$, called a jumping point. Therefore, the derivative of $W_{i}$ in the $x$-direction is

$\frac{d W_{i}}{d x}=\left\{\begin{array}{c}0 \\ \pm 2 \delta\left(\frac{d Y_{i}}{d x}\right) \text { for a jumping point }\end{array}\right.$

This assumption corresponds to the mathematical definition of $W_{i}$ except at jumping point. Then Eq. (11) rewritten to

$\frac{d}{d x}\left(\rho D_{\eta_{i}} \frac{d \eta_{i}}{d x}\right)=\rho u \frac{d}{d x}\left(\eta_{i}-W_{i} Y_{i}\right)+\frac{d}{d x}\left(W_{i} \rho D_{Y i} \frac{d Y_{i}}{d x}\right)$

After integrating the Eq. (13) on $x$ and divide both sides of the equation by $\rho$, thus the diffusion coefficient of $\eta_{i}$ can be written as

$D_{\eta_{i}} \frac{d \eta_{i}}{d x}=\frac{1}{\rho} \int \rho u \frac{d}{d x}\left(\eta_{i}-W_{i} Y_{i}\right) d x+W_{i} D_{Y i} \frac{d Y_{i}}{d x}$

Transport equation of progress variable, $\eta$, is obtained with the superposition of $\eta_{i}, i=1$ to $N_{s}$. Therefore the diffusion coefficient of progress variable, $D_{\eta}$, is obtained $D_{\eta}=\left(\sum_{i} c_{i} D_{\eta_{i}} \frac{d \eta_{i}}{d x}\right) /(d \eta / d x)$. Using Eq. (14), it can be rewritten as

$D_{\eta}=\frac{1}{d \eta / d x} \sum_{i=1}^{n} c_{i}\left[W_{i} \frac{\lambda}{\rho c_{p} L e_{i}} \frac{d Y_{i}}{d x}+\frac{1}{\rho} \int \rho u \frac{d}{d x}\left(\eta_{i}-W_{i} Y_{i}\right) d x\right]$

From the RHS of Eq. (15), the diffusion coefficient of $\eta$ includes two terms as following

$D_{\eta, I}=\frac{1}{d \eta / d x} \sum_{i=1}^{n} c_{i}\left[W_{i} \frac{\lambda}{\rho c_{p} L e_{i}} \frac{d Y_{i}}{d x}\right]$

$D_{\eta, I I}=\frac{1}{d \eta / d x} \sum_{i=1}^{n} c_{i}\left[\frac{1}{\rho} \int \rho u \frac{d}{d x}\left(\eta_{i}-W_{i} Y_{i}\right) d x\right]$

The DJHC-I is chosen to study the role of mass fraction and the ACV progress variable on two terms of $D_{\eta, I}$ and $D_{\eta}$, II. The $\mathrm{HO}_{2}$ as an intermediate species is selected to form $\eta_{\mathrm{HO}_{2}}$. Time progress of $Y_{\mathrm{HO}_{2}}, \eta_{\mathrm{HO}_{2}}$ and $\eta_{\mathrm{HO}_{2}}-W_{\mathrm{HO}_{2}} Y_{\mathrm{HO}_{2}}$ are presented in Fig. 2 at the mixture fraction equal to 0.0549 which is close to the most reactive mixture fraction. As it is shown, the behavior of the two diffusion terms are dramatically changed when the $\mathrm{YHO}_{2}$ changes the trend from the producing to consuming. At this turning point, $W_{\mathrm{HO}_{2}}$ changes sign and $D_{\eta, I}$ change from positive to negative values. $D_{\eta}$, II is made up of integration of the mass flux of $\frac{d}{d x}\left(\eta_{i}-W_{i} Y_{i}\right)$ in the $x$-direction. The $\mathrm{Y}_{\mathrm{HO}_{2}}$ is almost monotonic for $t<5 \mathrm{~ms}$ and it is nearly equal to $\eta_{i}$, therefore and $\eta_{i}-W_{i} Y_{i}$ is negligible and results in the small magnitude of the $D_{\eta}$, II

\section{Variable Ignition Mixing Layer (VIML)}

A non-reacting counter-flow stream is a standard method to make an initial condition for the ignition counter-flow flamelet solver. This initializing method represents the assumption that the fuel-oxidizer mixing time scale is smaller than the reaction time scale. This assumption is violated when reactions take place during the mixing process [24]. For instance, hydrogen is highly diffusive and reactive than larger fuel molecules. This specific behavior can reduce the autoignition delay time in hydrogen blended fuels and syngas $[35,36]$. Consequently, it is needed to take the reaction into account as well as the molecular diffusion at the same time. 


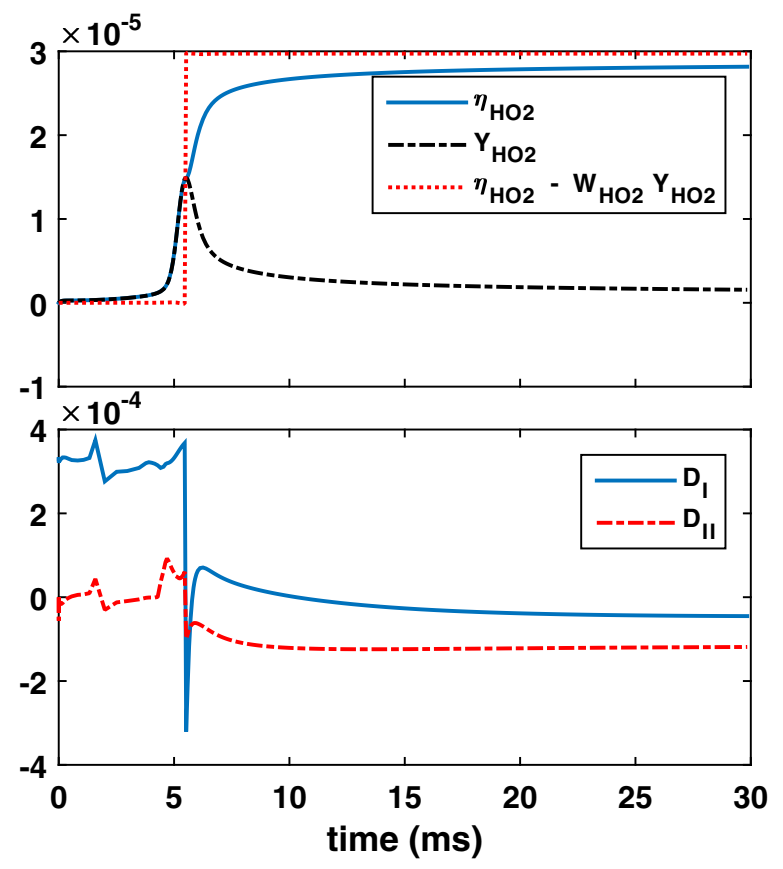

Fig. 2. effects of the $\mathrm{YHO}_{2}$ progress at $\zeta=0.0549$ as most reactive mixture fraction on the diffusion coefficient of $\eta_{\mathrm{HO}_{2}}$.

For this purpose, Abtahizadeh et al. [24] introduced the Ignition Mixing Layer (IML). This method provides autoignition prediction along with the molecular mixing of fuel and oxidizer streams. The fuel and oxidizer are assumed to be stagnant and adjacent to each other at $t=0$. The mixture fraction profile has a stepwise configuration and the strain rate is zero. The stepwise mixture fraction leads to a large dissipation rate, $\chi=2 D(\partial \zeta / \partial x)^{2}$, but increases molecular diffusion as well at the contact surface of a fuel and an oxidizer. The molecular diffusion reduces the mixture fraction gradient, $\partial \zeta / \partial x$, and therefore the dissipation rate is declining during the molecular mixing process.

Counterflow diffusion flames have an inlet boundary condition on both sides so that the fuel and oxidizer streams have a constant composition and temperature at the boundaries. Therefore, the application of a 2-D look-up table is limited to a case with a uniform and consistent fuel/oxidizer stream. In a case that there are more than two inflow streams, such as the Sandia piloted flames [37], as well as non-uniformity of oxidizer and fuel mixture composition or temperature along inflow boundary conditions, such as Delft JetHot Coflow burner [38], the dimensions of flamelet libraries, are needed to be increased to overcome the non-uniformity or multi inflow streams.

The VIML method is introduced to generate a two-dimensional look-up table for non-uniform fuel/oxidizer stream as well as a multi-stream inflow boundary condition. This model takes advantage of the IML method that provides a zero strain rate and zero velocity at the initial condition. Utilizing these features, the mixture initial condition could vary along the $x$-coordinate. This method reduces the computational cost and size of the look-up table by retaining the two dimensions of the look-up table. For instance, assume the mixture fraction and the progress variable is divided into the $\mathrm{N}$ interval for $\mathrm{M}$ thermochemical properties, and $\mathrm{P}$ point of the $\beta$ eta-PDF function. Accordingly, the 2-D table stores $\mathrm{N}^{2} \times \mathrm{P}^{2} \times \mathrm{M}$ elements. Adding the third dimension with $\mathrm{N}$ interval increases the size of the table to $\mathrm{N}^{3} \times \mathrm{P}^{3} \times \mathrm{M}$ which significantly increases the look-up table size. Based on experience, the file size of a 2-D look-up table of $201^{2} \times 5^{2} \times 30$ elements is about $528 \mathrm{MB}$ while extending this table to $3-\mathrm{D}$ with the same resolution, the ex-
Table 1

Boundary condition of Laminar Jet in Hot Coflow (LJHC) [39].

\begin{tabular}{|c|c|c|c|c|c|c|c|}
\hline \multicolumn{5}{|c|}{ Coflow oxidizer } & \multicolumn{3}{|c|}{ Fuel jet } \\
\hline$X_{02}$ & $X_{N 2}$ & $X_{\mathrm{H} 2 \mathrm{O}}$ & $X_{\mathrm{CO} 2}$ & $T(K)$ & $X_{\mathrm{CH} 4}$ & $X_{N 2}$ & $T(K)$ \\
\hline 0.036 & 0.732 & 0.145 & 0.087 & 1530 & 0.170 & 0.830 & 1150 \\
\hline
\end{tabular}

pected dramatically table size is about $610 \mathrm{~GB}$. The only way to generate high dimensional FGM table has reduced the resolution of the look-up table means to lower accuracy and higher numerical error during the interpolation procedure.

In Fig. 3, the mixture fraction and temperature at initial condition $(t=0)$ and progress of mixture $(t>0)$ are shown for Sandia flame D. This flame has three streams of fuel jet $(\zeta=1)$, pilot $(\zeta=0.27)$ and oxidizer coflow $(\zeta=0)$ which is described later in this paper. The mixture fraction distribution in the 1-D dimension is the same as the physical domain.

$$
\zeta(x, 0)=\left\{\begin{array}{l}
10 \leq X<r_{\text {jet }} \\
0.27 r_{\text {jet }} \leq X<r_{\text {pilot }} \\
0 r_{\text {jet }} \leq X
\end{array}\right.
$$

\section{1-D laminar flame}

The one-dimensional simulation of the Laminar Jet in Hot Coflow (LJHC) $[33,34]$ is conducted to validate the ACV-FGM method. The oxidizer stream of the LJHC burner is a combustion product of the lean $\mathrm{CH} 4$ /oxidizer mixtures corresponding to the $\varphi=0.8$. The oxidizer stream temperature is $1530 \mathrm{~K}$, which is above the fuel autoignition temperature to guarantee the Mild combustion regime. The fuel stream carrying the $\mathrm{CH} 4 / \mathrm{N} 2$ at the temperature $1150 \mathrm{~K}$. Spontaneous Raman scattering was used to measure the flame temperature and major species $\left(\mathrm{CO}, \mathrm{CO}_{2}, \mathrm{~N}_{2}, \mathrm{H}_{2}, \mathrm{H}_{2} \mathrm{O}\right.$, $\mathrm{CH}_{4}$, and $\mathrm{O}_{2}$ ). Table 1 describes oxidizer and fuel mixture compositions and temperatures.

The governing equations of one-dimensional reactive flow are as follow [24]

$$
\begin{aligned}
& \frac{\partial \rho}{\partial t}+\frac{\partial \rho u}{\partial x}=0 \\
& \frac{\partial\left(\rho Y_{i}\right)}{\partial t}+\frac{\partial\left(\rho u Y_{i}\right)}{\partial x}=\frac{\partial}{\partial x}\left(\frac{\lambda}{L e_{i} c_{p}} \frac{\partial Y_{i}}{\partial x}\right)+\omega_{i} \\
& \frac{\partial(\rho h)}{\partial t}+\frac{\partial(\rho u h)}{\partial x}-\frac{\partial}{\partial x}\left(\frac{\lambda}{c_{p}} \frac{\partial h}{\partial x}\right)=\frac{\partial}{\partial x}\left[\frac{\lambda}{c_{p}} \sum_{i=1}^{N s}\left(\frac{1}{L e_{i}}-1\right) h_{i} \frac{\partial Y_{i}}{\partial x}\right]
\end{aligned}
$$

The Species continuity equation, Eq. (19), is solved for $N_{S}-1$, where $N_{S}$ is a total number of chemical species. Initial conditions for velocity, $u$, species mass fraction, $Y_{i}$, and enthalpy, $h$, are as follow

$u(x, 0)=0$

$Y_{i}(x, 0)= \begin{cases}Y_{i, f u} & x<0 \\ Y_{i, o x} & x \geq 0\end{cases}$

$h(x, 0)=\left\{\begin{array}{l}h_{f u} x<0 \\ h_{o x} x \geq 0\end{array}\right.$

where density, $\rho$, thermal conductivity, $\lambda$, constant temperature specific heat, $c_{p}$ are the thermal properties of the species i. Ns is the number of chemical species and $\dot{\omega}$ is a chemical source term. 

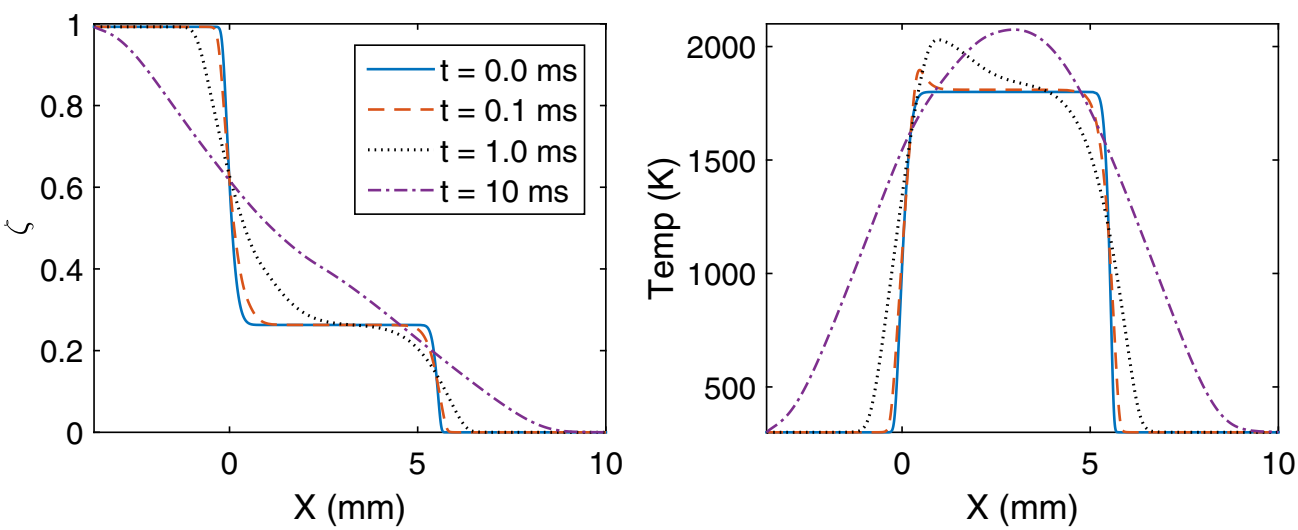

Fig. 3. Mixture fraction and temperature Variable Ignition Mixing Layer for Sandia flame D. $0<X<3.6$ is fuel jet, $3.6<X<9.1$ is the pilot, $9.1<X$ is oxidizer stream.

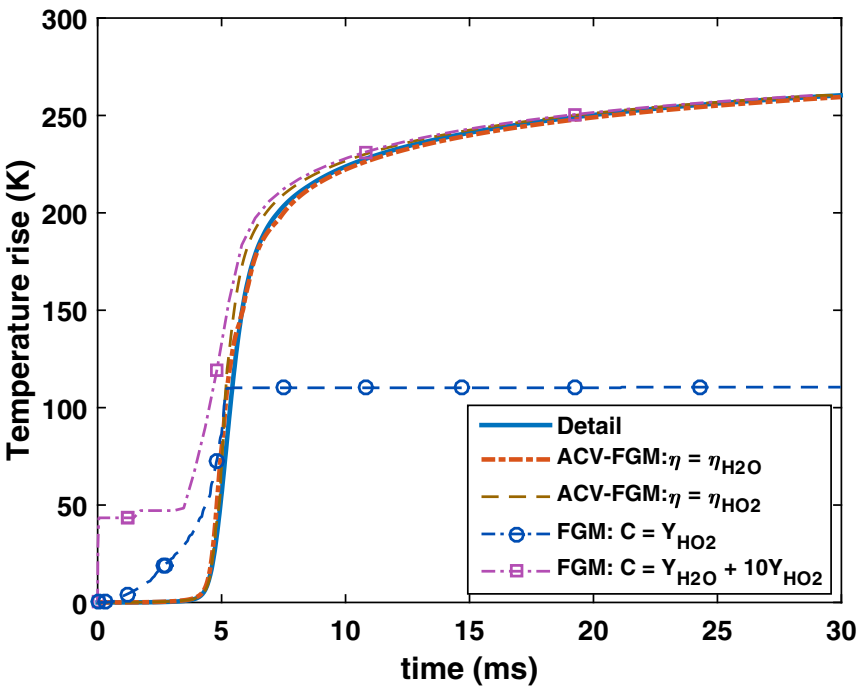

Fig. 4. Autoignition delay time of the detail, ACV-FGM, and FGM model.

Constant non-unity Lewis numbers are assumed, which takes preferential diffusion of species into account.

1-D laminar flame simulation is a primary step to validate ACV-FGM. The predicted autoignition delay time, temperature, and chemical species are compared with the detail solution as well as the classical FGM results. The in-house Chem1D code is used to solve the 1-D laminar flame applying the IML method. The chemical kinetics are resolved based on the GRI 3.0 mechanism. The results of the 1-D laminar flame are used to generate the ACVFGM look-up table, including temperature, diffusion coefficient, and chemical species tabulated in mixture fraction - progress variable space. An in-house code is developed to solve the transport equation of mixture fraction and progress variable for 1-D laminar flame configuration using the ACV-FGM look-up table to retrieve the mixture thermochemical properties.

Figure 4 indicates the temperature rise for ACV-FGM and FGM model simulation. The progress variable of the ACV-FGM and FGM method indicated by $\eta$ and $\mathrm{C}$, respectively. The $\mathrm{HO}_{2}$ mass fraction as the intermediate species is selected to make the $\eta=\eta_{\mathrm{HO}_{2}}$ and generate the ACV-FGM look-up table. The accurate prediction of autoignition delay time and temperature rise shows the generated look-up table is bijective to thermochemical time-state space. Therefore, it indicates the bijective tabulation can be achieved even with intermediate species. This conclusion is also valid for $\eta=$ $\eta_{\mathrm{H}_{2} \mathrm{O}}$ as it shows good agreement with the detail solution.
The FGM method tabulated were based on $\mathrm{C}=\mathrm{Y}_{\mathrm{HO}_{2}}$ and $\mathrm{C}=$ $Y_{\mathrm{H}_{2} \mathrm{O}}+10 \mathrm{Y}_{\mathrm{HO}_{2}}$ failed to predict the autoignition delay time. However, the final temperature has good agreement with the detailed solution for FGM : $\mathrm{C}=\mathrm{Y}_{\mathrm{H}_{2} \mathrm{O}}+10 \mathrm{Y}_{\mathrm{HO}_{2}}$. for case FGM: $\mathrm{C}=\mathrm{Y}_{\mathrm{HO}_{2}}$ the temperature rise is stopped after $t=0.005 \mathrm{~s}$, indicate the flamelet data are not available and it is lost in tabulation procedure. For case FGM: $\mathrm{C}=\mathrm{Y}_{\mathrm{H}_{2} \mathrm{O}}+10 \mathrm{Y}_{\mathrm{HO}_{2}}$ the autoignition delay time is not correct, and the pre-ignition data is lost. However, the temperature rise is appropriately predicted after autoignition delay time as a result of the partially monotonic behavior of $\mathrm{Y}_{\mathrm{H} 2 \mathrm{O}}$ after the temperature rise.

The temperature, $\mathrm{Y}_{\mathrm{CO}}$, and $\mathrm{Y}_{\mathrm{NO}}$ are depicted in Fig. 5 for three cases of detail solution, ACV-FGM, and FGM result. The time slice is chosen from $t=3 \mathrm{~ms}$, which is before the ignition and temperature rise. The progress variable for FGM is defined as $C=Y_{\mathrm{H}_{2} \mathrm{O}}+$ $10 Y_{\mathrm{HO}_{2}}+Y_{\mathrm{NO}}$ and for the ACV-FGM is $\eta=\eta_{\mathrm{H}_{2} \mathrm{O}}+10 \eta_{\mathrm{HO}_{2}}+\eta_{\mathrm{CO}}$. As it is shown, the incorrect temperature rises for the FGM model is appeared at $t=3 \mathrm{~ms}$, which can be interpreted as the unsuccessful FGM look-up table generation for pre-ignition duration. The temperature rises error is deteriorated along the time, and for $t=7 \mathrm{~ms}$ it has the minimum error for lean to stoichiometric mixture fraction, $\zeta_{\text {st }}=0.0892$. However, for the fuel-rich mixture fraction, the temperature is overpredicted. The $\mathrm{CO}$ and NO mass fraction prediction follow the temperature trend in which the maximum error occurs in the pre-ignition duration as well as $\zeta>\zeta_{\text {st. }}$. The ACV-FGM method can precisely predict the temperature rise and $\mathrm{CO}$ and NO mass fraction for all time slices and mixture fraction from 0 to 1 .

\section{Large eddy simulations}

Large eddy simulations are conducted to validate the VIML and ACV-FGM method for the case of turbulent jet flames. The study of the Sandia piloted flames as multi-stream burners are aimed at investigating the chemical species prediction within the domain, including the $\mathrm{CO}$ and NOx as well as the effects of fuel jet Reynolds number. The LES of the Delft Jet-Hot Coflow burner (DJHC-I) is conducted to verify the VIML and ACV-FGM methods to simulate the lift-off height of the turbulent jet flame which is fed by the nonuniform oxidizer mixture composition and temperature.

\subsection{LES numerical scheme}

The large eddy simulation numerical scheme is the same as one used in references [29,40], which is briefly introduced in this section. The LES equations follow the implicitly filtered Navier-Stokes equations with the mesh-size filter width $\Delta_{f}$. In this approach, filtered equations of mass and momentum conservation govern the flow field and another two filtered transport equations 

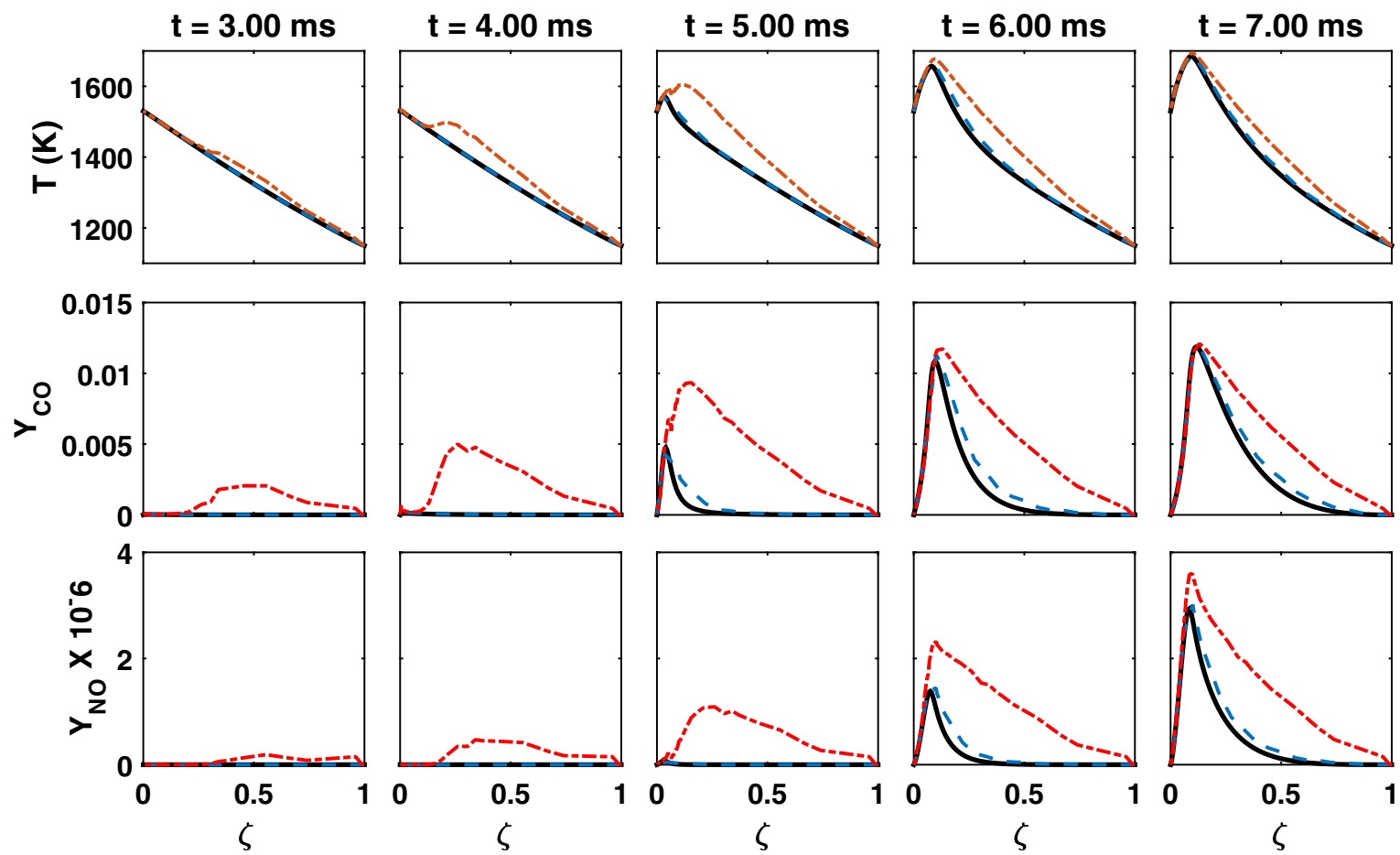

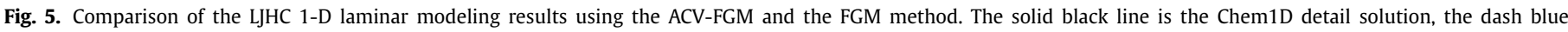

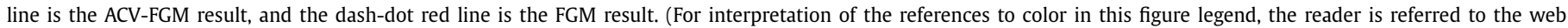
version of this article.)

for FGM table coordinate, mixture fraction and progress variable, govern the tabulated combustion chemistry.

$\frac{\partial \bar{\rho}}{\partial t}+\frac{\partial \bar{\rho} \tilde{u}_{j}}{\partial x_{j}}=0$

$\frac{\partial\left(\bar{\rho} \tilde{u}_{i}\right)}{\partial t}+\frac{\partial\left(\bar{\rho} \tilde{u}_{i} \tilde{u}_{j}\right)}{\partial x_{j}}$

$=\frac{\partial \bar{p}}{\partial x_{j}}+\frac{\partial}{\partial x_{j}}\left[\left(\mu_{L}+\mu_{T}\right)\left(\frac{\partial \tilde{u}_{i}}{\partial x_{j}}+\frac{\partial \tilde{u}_{j}}{\partial x_{i}}-\frac{2}{3} \frac{\partial \tilde{u}_{k}}{\partial x_{k}} \epsilon_{i j}\right)\right]$

$\frac{\partial(\bar{\rho} \tilde{\zeta})}{\partial t}+\frac{\partial(\bar{\rho} \tilde{u} \tilde{\zeta})}{\partial x_{j}}=\frac{\partial}{\partial x_{j}}\left[\left(\bar{\rho} \bar{D}_{\zeta}+\frac{\mu_{T}}{S c_{T}}\right) \frac{\partial \tilde{\zeta}}{\partial x_{j}}\right]$

$\frac{\partial(\bar{\rho} \tilde{\eta})}{\partial t}+\frac{\partial(\bar{\rho} \tilde{u} \tilde{\eta})}{\partial x_{j}}=\frac{\partial}{\partial x_{j}}\left[\left(\bar{\rho} \bar{D}_{\eta}+\frac{\mu_{T}}{S c_{T}}\right) \frac{\partial \tilde{\eta}}{\partial x_{j}}\right]+\overline{\omega_{\eta}}$

Filtered quantities are indicated with bar and density-weighted quantities with a tilde. $\bar{\rho}, \bar{D}_{\zeta}, \bar{D}_{\eta}$, and $\overline{\omega_{\eta}}$ are retrieved from the FGM library. The conductivity $\lambda$ and viscosity $\mu_{L}$ are modeled as simplified functions of PDF averaged temperature [4,41], which is stored as a look-up variable in the FGM table.

$\mu_{L}=1.67 \times 10^{-8}(\tilde{T} / 298)^{0.51} c_{p}$

$\lambda=1.67 \times 10^{-5}(\tilde{T} / 298)^{0.69} c_{p}$

The eddy diffusivity, $\mu_{T} / S c_{T}$, calculated based on the proposed model by Vreman et al. [42] and the fixed turbulent Schmidt number, $S c_{T}=0.4$.

The $\beta$-PDF method is used to model turbulence-chemistry interaction and thermochemical properties statistically. In this procedure, the progress variable is normalized so that the statistical de- pendency is negligible. Generally, the probability density function of quantity $\varphi$ is determined as $P(\varphi)=P\left(\varphi: \tilde{\varphi}, \widetilde{\varphi^{\prime \prime 2}}\right)$ where $\tilde{\varphi}$ and $\widetilde{\varphi^{\prime \prime}} 2$ are mean and variance respectively. The $\beta$-PDF integrated FGM table for the DJHC burner has $201 \times 5 \times 201 \times 5$ grid points in $\zeta, \zeta$ var and $\eta, \eta_{\text {var }}$ dimensions. An algebraic equation is used to obtain, $\widetilde{\varphi^{\prime \prime 2}}=\alpha \Delta X^{2}\left(\partial \tilde{\varphi} / \partial X_{j}\right)^{2}$, where $\alpha=1 / 12$ based on Taylor expansion [40].

Neumann boundaries are applied to the side planes and the outflow plane for velocity, mixture fraction and progress variable as well as pressure at inflow and outflow plane. The pressure side plane boundary condition is of Dirichlet type. The mixture fraction and progress variable are unperturbed at the inflow while a filtered random noise generator is used to generate fluctuation of the inflow velocity [29]. Nearly isotropic homogeneous turbulence at the inflow is reproduced by using a spatially box-filter with the size of $\Delta_{f}=D / 4$ and a temporal filter of $\Delta_{T}=\Delta t / 4$.

The spatial discretization is implemented on the staggered Cartesian mesh grid using a second-order central differencing standard finite-volume method for mass and momentum continuity equation. Hybrid time stepping is used as temporal discretization. A third-order Adams-Bashforth method is used for the convective terms as well as a forward Euler for the viscous terms and source terms, providing more stability [29].

The transport equation of mixture fraction and ACV progress variable are discretized with third-order Van Leer's MUSCLE scheme, which is Total Variation Diminishing (TVD). A combination of MPI and OpenMP protocol on a multi-block platform is used to parallelize the computational process. A multi-grid method is applied to solve Poisson's equation which is extensively described in [29]. In Fig. 6, the Lewis numbers of selected species are illustrated for DJHC-I and Sandia flame D obtained by fitting results computed with the Hirschfelder-Curtiss approximation [43]. The Chem1D set to calculate the Lewis number of the chemical species using the mixture-averaged diffusion coefficient which leads to a 


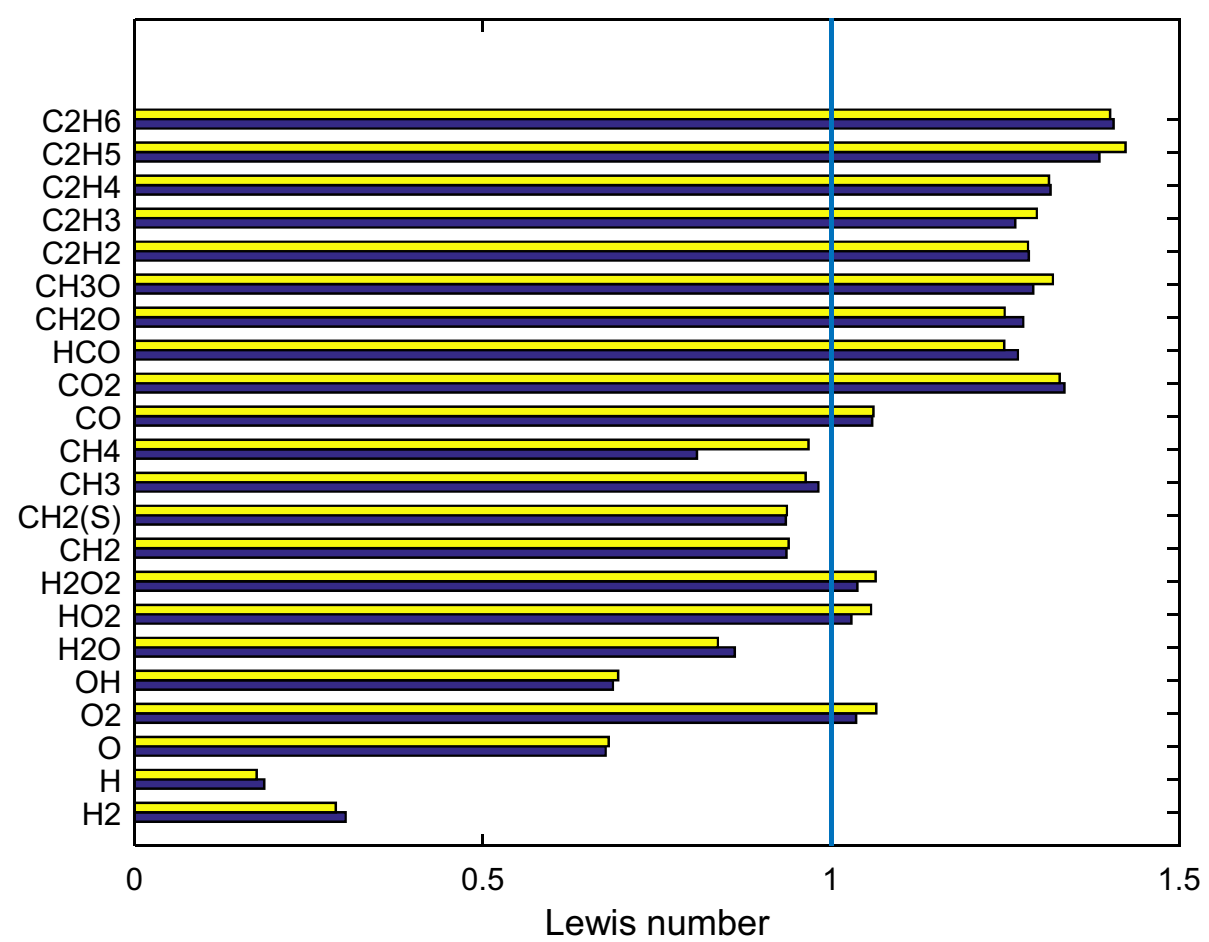

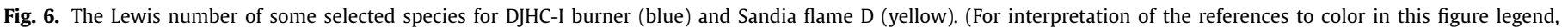
the reader is referred to the web version of this article.)

small difference of the species Lewis number for DJHC and Sandia flame.

\subsection{The Sandia piloted flames}

The Sandia piloted flames D, E, and F have a three-inflow stream including a partially premixed fuel jet, pilot, and oxidizer stream. The fuel jet leaves the round nozzle with $7.2 \mathrm{~mm}$ in diameter with a volumetric ratio of fuel to air is $1 / 3$, corresponding to $\zeta=1$. The fuel jet is surrounded by the pilot stream with an outer diameter $18.2 \mathrm{~mm}$ and consists of the lean combustion products of $\mathrm{CH} 4 /$ air composition at $\phi=0.75$, providing the high-temperature stream at $1880 \mathrm{~K}$, corresponding to $\zeta=0.27$. The wind tunnel stream with a square cross-section $30 \mathrm{~cm} \times 30 \mathrm{~cm}$ surrounded the jet and pilot stream. Sandia flames D, E, and F have Reynolds number equal to $22,400,33,600$, and 44,800 , respectively.

The experimental measurement was conducted over the domain from jet exit to axially $Z=80 \mathrm{D}$ and radially $R=10 \mathrm{D}$. However, the computational domain is extended axially to $121 \mathrm{D}$ to avoid the numerical effects of the outflow boundary condition. The lateral extension of the computational domain is determined based on the expansion of the nonreactive free turbulent jet. The half cone of turbulent jet expansion is approximately equal to $11.8^{\circ}$; thus the radial expansion of a free turbulent jet can be obtained as $R=Z / 5$. A Cartesian computational domain is consists of $149 \times 149 \times 512$ grid that extending to 53D, 150D laterally and axially respectively. This domain allows a larger explicit time-step compared to cylindrical grids [29]. The computational domain contains $80 \%$ of total grid points (9.1 million out of 11.3 million grid points) up to $Z=80 \mathrm{D}$. The grid is stretched from the nozzle exit in all three directions. The smallest cell size at the nozzle exit is $D / 15$ in the horizontal direction and $\mathrm{D} / 10$ in the axial direction. The solution is initialized with wind tunnel mixture properties e.g., zero mixture fraction and axial velocity of $0.9 \mathrm{~m} / \mathrm{s}$. The experimental data at $Z=D$ is used as the inflow boundary condition. The constant time step, $2.0 \times 10^{-6} \mathrm{~s}$, is applied to maintain the CFL num-
Table 2

species weight factor $C_{i}$ for Sandia flame and DJHC-I burner.

\begin{tabular}{lllllllll}
\hline & & $\mathrm{O}_{2}$ & $\mathrm{CH}_{4}$ & $\mathrm{C}_{2} \mathrm{H}_{6}$ & $\mathrm{CO}_{2}$ & $\mathrm{H}_{2} \mathrm{O}$ & $\mathrm{OH}$ & $\mathrm{HO}_{2}$ \\
\hline$C_{i, \text { Sandia }}$ & & 1 & 1 & 0 & 1 & 1 & 0 & 0 \\
$C_{i, \text { DJHC-I }}$ & $\mathrm{C} 1$ & -1 & -1 & -1 & 1 & 1 & 10 & 100 \\
& $\mathrm{C} 2$ & -1 & -1 & -1 & 1 & 1 & 10 & 100 \\
& $\mathrm{C} 3$ & 1 & 1 & 1 & 1 & 1 & 10 & 100 \\
\hline
\end{tabular}

ber less than 0.2 . To ensure the flow field is statistically stationary, the averaging is done from $t=0.200 \mathrm{~s}$ up to $t=0.325 \mathrm{~s}$, while the transient jet flow reaches already 80D at $t=0.0625 \mathrm{~s}$.

To produce the 2-D FGM look-up table, the 1-D laminar flame is modeled using the VIML method and chemical kinetics is solved based on the GRI 3.0 reaction mechanisms. The initial condition of this flame is reproduced based on the boundary condition of the burner, here for Sandia flames the fuel stream $0 \leq X<3.6$, the pilot $3.6 \leq X<9.1$, and oxidizer stream $X \geq 9.1$, as it is illustrated in Fig. 1 for $t=0$, all dimensions are in millimeter. Species weight factor, $C_{i}$, are listed in Table 2 to calculate the ACV-FGM progress variable.

The mean and variance of mixture fraction and temperature are depicted in Figs. 7-9 for Sandia flame D, E, and F, respectively. The mean value of the mixture fraction and temperature have a reasonable agreement with the experimental data. Deviation of mixture fraction and temperature variance are decreasing along the jet axis, and variances are fairly good for $Z \geq 15 \mathrm{D}$.

Barlow and Frank [37] reported the Sandia D flame showed a slight degree of local flame extinction while increasing the fuel jet Reynolds number enhances the probability of the local extinction. At the $Z=30 \mathrm{D}$, the local extinction of $\mathrm{D}$ and $\mathrm{E}$ flame were low while flame $F$ had a high probability of the local extinction. The LES results of the Sandia F flame shows that the temperature for $r / D<5$ is over predicted while the temperature variance is under predicted, Fig. 9. It shows that the developed model needs further 

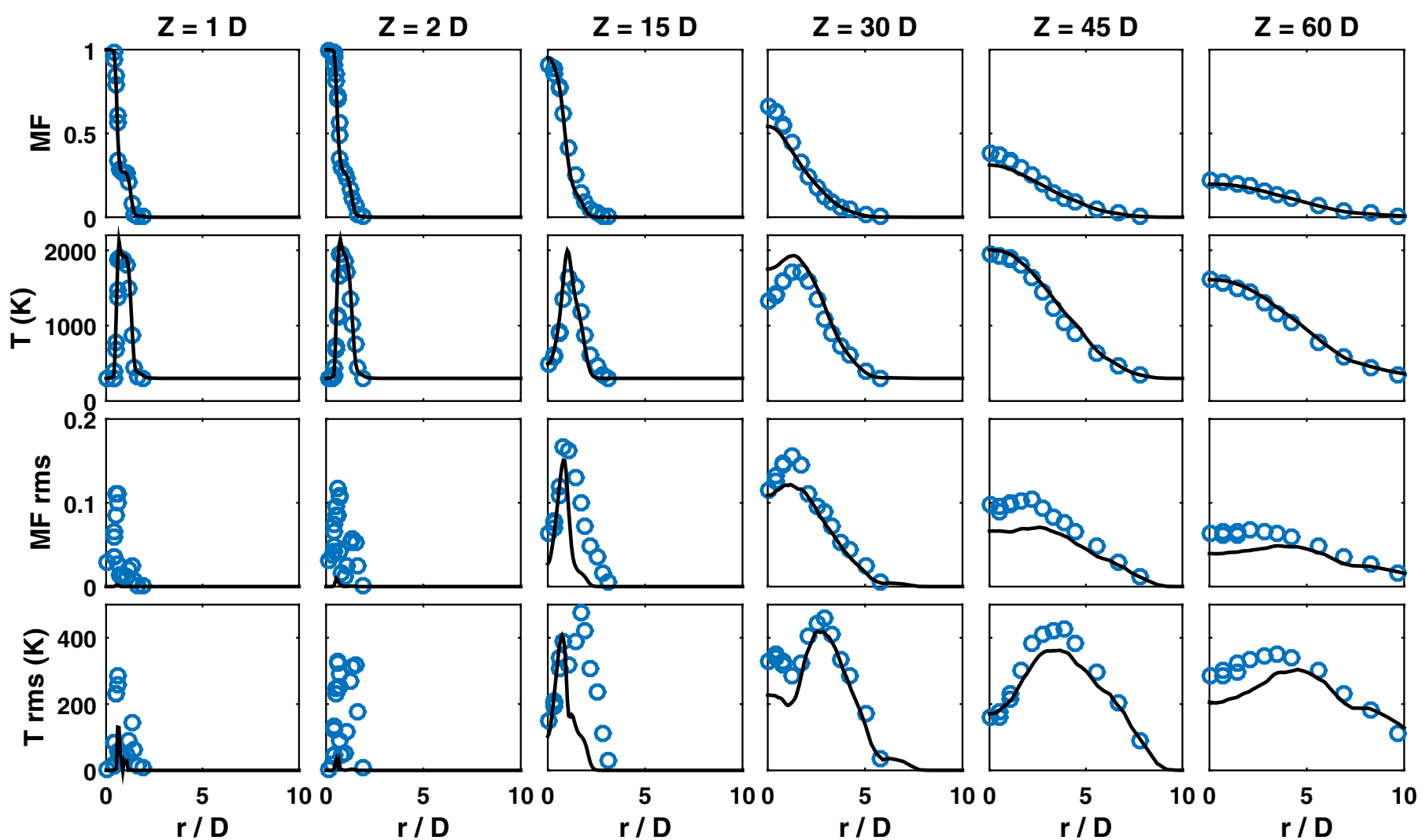

Fig. 7. Mean and RMS of mixture fraction and temperature in Sandia D flame. The circles are experimental data and solid lines are LES results.
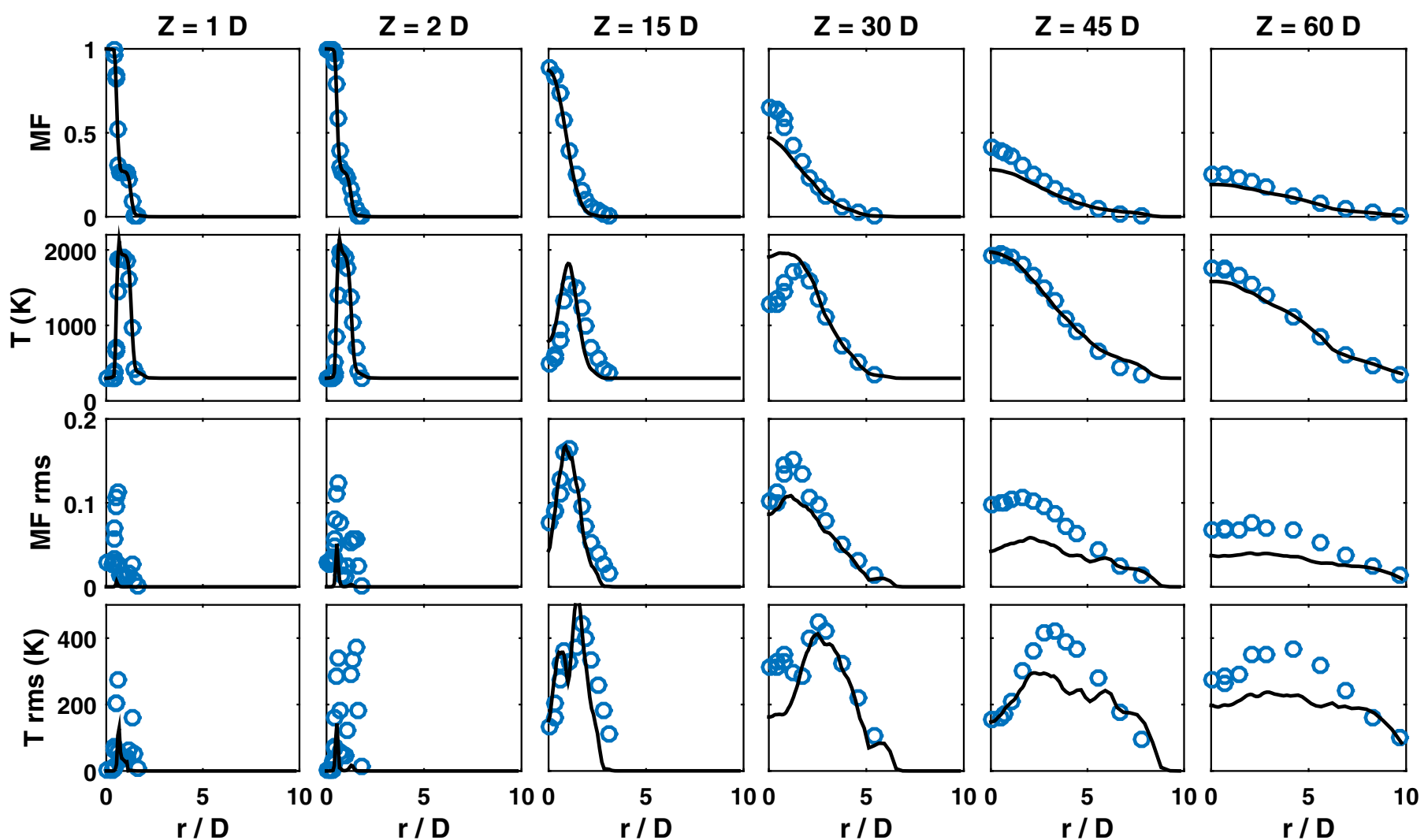

Fig. 8. Mean and RMS of mixture fraction and temperature in Sandia E flame. The circles are experimental data and solid lines are LES results. 

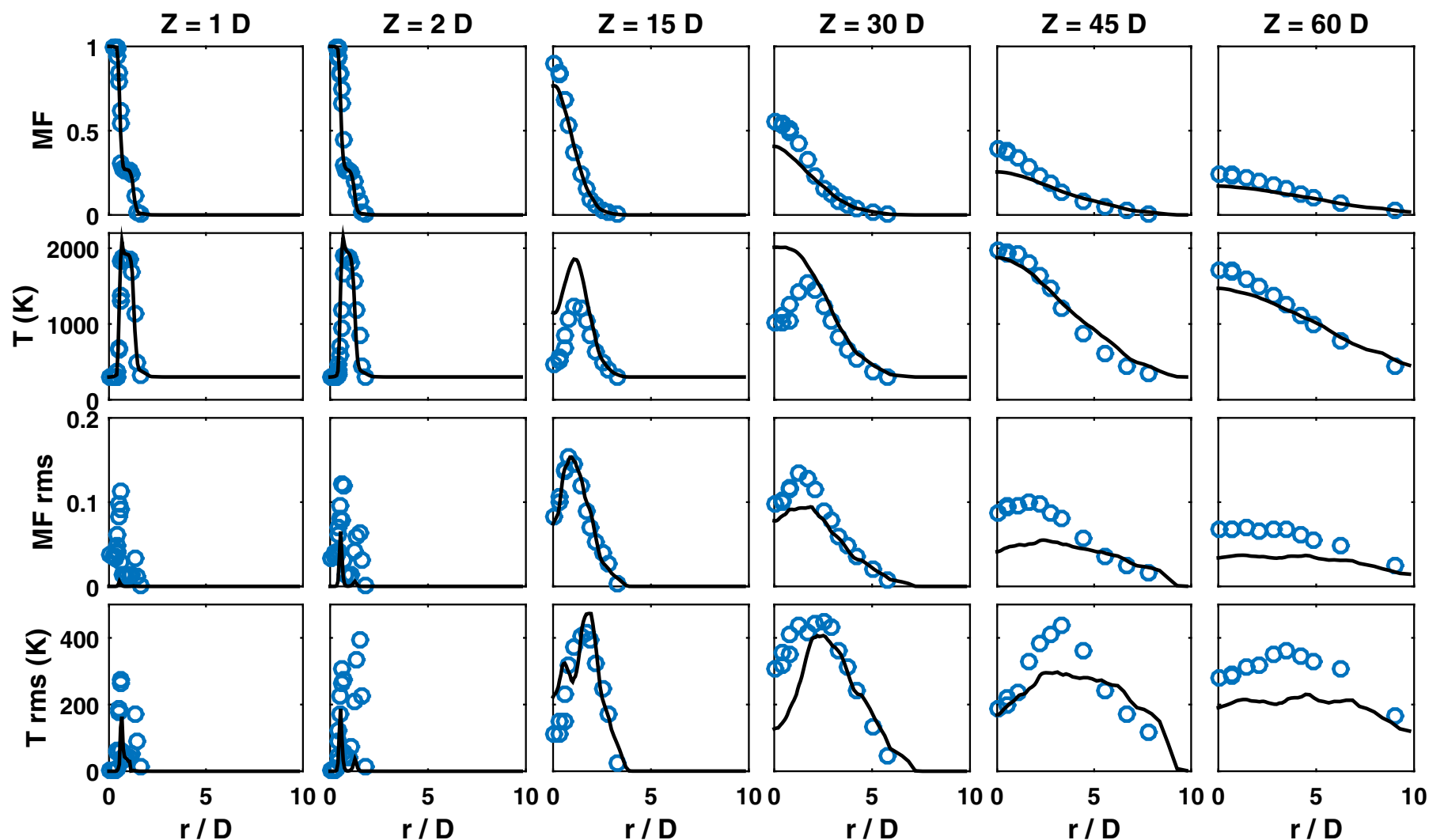

Fig. 9. Mean and RMS of mixture fraction and temperature in Sandia F flame. The circles are experimental data and solid lines are LES results.

improvement to simulate the local extinction phenomenon more realistic.

Figure 10 indicates Sandia D flame's experimental data of $\mathrm{O}_{2}$, $\mathrm{CH}_{4}, \mathrm{CO}_{2}, \mathrm{OH}, \mathrm{CO}$, and $\mathrm{NO}$ mass fraction compared to species mass fraction retrieved from the look-up table. The results show that the 2-D look-up table generated by ACV-FGM along with the VIML method combined with large eddy simulation of the Sandia piloted flame accurately predicts the chemical species mass fraction.

\subsection{The Delft Jet-Hot Coflow burner}

The Delft Jet-Hot Coflow burner (DJHC) test stand was developed at Delft University of Technology to mimic the flameless combustion regime [38]. For the DJHC-I configuration, the fuel jet Reynolds number is equal to 4500 . The fuel is discharged through a $4.5 \mathrm{~mm}$ nozzle diameter into the hot oxidizer coflow. A partially premixed secondary burner produces lean combustion products as an oxidizer coflow. This burner is located within an annulus with a diameter of $82.8 \mathrm{~mm}$, surrounding the fuel jet and its cooling jacket. The radial profile of the mixture fraction of the secondary burner is varying, leads to varying temperature and oxygen mass fraction with the radial position. Downstream of the jet exit is unconfined and the flame is surrounded by fresh air.

Several cases were tested and reported on the DJHC burner test stand $[31,38,44]$. In this paper, the DJHC-I configuration is simulated using a large eddy simulation. The fuel jet is consists of Dutch Natural Gas (DNG), which is composed of $\mathrm{N}_{2}, \mathrm{CH}_{4}, \mathrm{C}_{2} \mathrm{H}_{6}$, and $\mathrm{CO}_{2}$. The fuel jet and hot coflow properties are represented in Table 3. The hot coflow composition and temperature are varying radially. The temperature and composition are significantly correlated and the maximum temperature $1540 \mathrm{~K}$ takes place approximately at minimum $\mathrm{O} 2$.
Table 3

Mean fuel jet and oxidizer coflow composition and maximum temperature and velocity [39].

\begin{tabular}{llllllll}
\hline & $T_{\max }$ & $v_{\max }$ & $Y_{\mathrm{O}_{2}}$ & $Y_{\mathrm{N}_{2}}$ & $Y_{\mathrm{CH}_{4}}$ & $Y_{\mathrm{C}_{2} \mathrm{H}_{6}}$ & $Y_{\mathrm{CO}_{2}}$ \\
\hline Fuel & 437 & 4.6 & 0.0000 & 0.2190 & 0.7064 & 0.0603 & 0.0143 \\
Coflow & 1540 & 34 & 0.0840 & N/A & N/A & N/A & N/A \\
\hline
\end{tabular}

Table 4

three FGM table generation methods to evaluate the VIML and ACV-FGM.

\begin{tabular}{lll}
\hline Case no. & 1D method & Progress variable \\
\hline C1 & IML & weighted summation \\
C2 & VIML & weighted summation \\
C3 & VIML & ACV-FGM \\
\hline
\end{tabular}

Table 4 briefly introduces three different FGM look-up tables. In the case $\mathrm{C1}$, the FGM look-up table is using the IML method and a progress variable that is defined based on the weighted summation of selected species mass fraction. This case is the duplication of the simulation results of Abtahizadeh et al. [40] with the oxidizer composition was assumed to correspond to the maximum coflow temperature and minimum $\mathrm{Y}_{\mathrm{O} 2}$. The coflow stream at the nozzle exit plane is radially non-uniform and the VIML is used to model this non-uniformity in case C2 and C3. The ACV-FGM is applied to the case C3 to study the capability of the modified model to simulate the lift-off height of the turbulent flame. The species weight factors used to build the ACV-FGM are described in Table 2.

The 10-million grid resolution is used for all cases. The experimental data are available from the nozzle tip to $150 \mathrm{~mm}(\sim 33 \mathrm{D})$. The computational domain is extended to $315 \mathrm{~mm}$ (70D) axially to reduce the effect of the numerical outflow boundary condition. The 

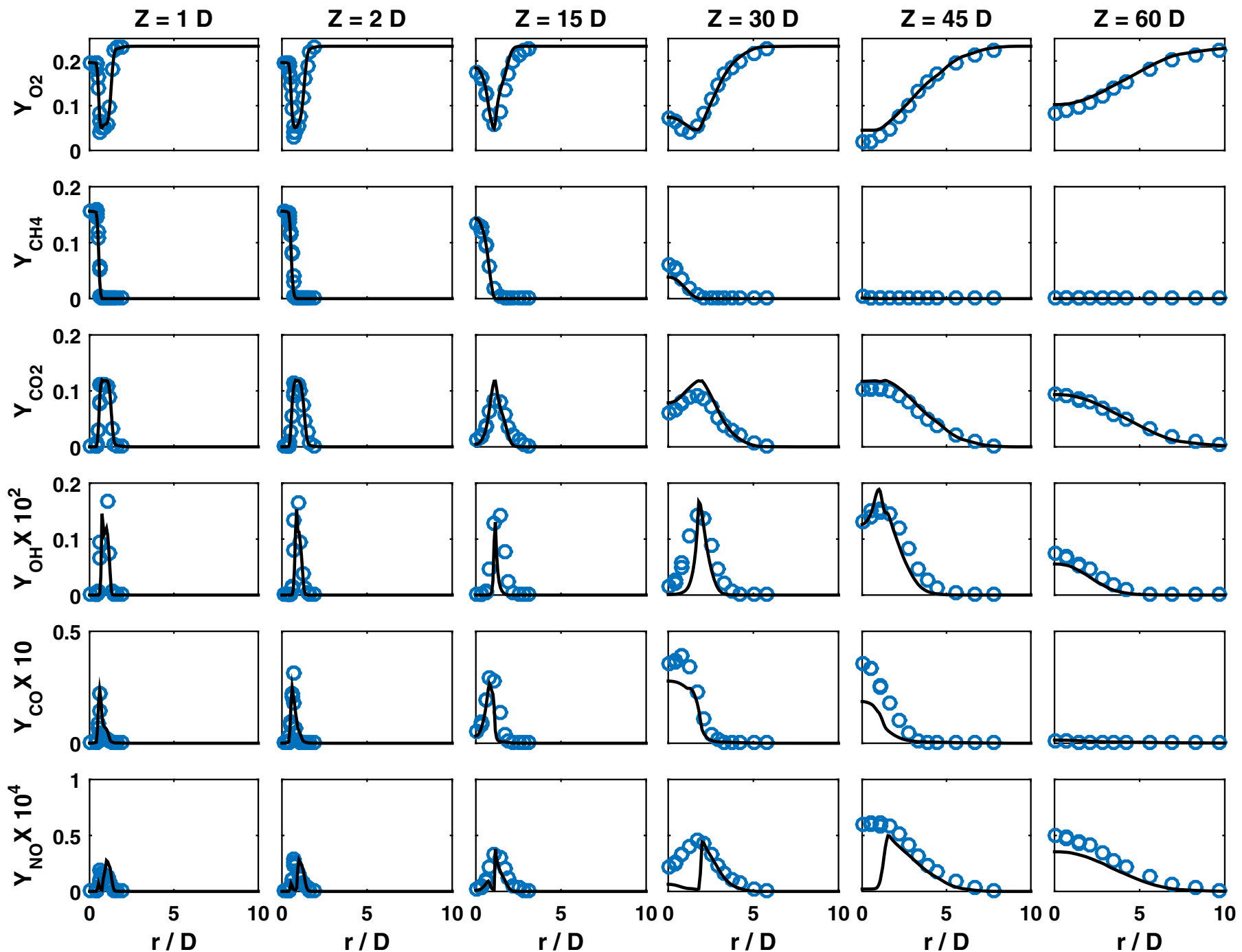

Fig. 10. The species mass fraction of Sandia D flame retrieved from the 2-D look-up table generated by the AVC-FGM along with VIML methods.

lateral extension of the computational domain is $65 \mathrm{~mm}(\sim 14.5 \mathrm{D})$, which is more than the maximum radial expansion of free turbulent jet, which is equal to $14 \mathrm{D}$ at $Z=70 \mathrm{D}$. The Cartesian grid point resolution is $145 \times 145 \times 512$, with clustered grid points in the axial direction. The grid points up to $Z=33 \mathrm{D}$ include $70 \%$ of the total grid points $(7.5 \mathrm{M}$ out of $10.7 \mathrm{M})$. The grid points are distributed to increase cell size from the nozzle tip in all three directions. The smallest cell size at the nozzle tip is $D / 20$ in both horizontal and axial directions. The computational domain is initialized using coflow properties and axial velocity of $3.5 \mathrm{~m} / \mathrm{s}$. The experimental data at $Z=3 \mathrm{~mm}$ is available, which is used as an inflow boundary condition.

A constant time step is applied and equal to $5 \times 10^{-6} \mathrm{~s}$, which retains the CFL number less than 0.4. Time-averaging is applied over about $0.4 \mathrm{~s}$. The mean and snapshots of temperature and $\mathrm{OH}$ distributions are shown in Figs. 11 and 12 respectively, at the central plane of the simulation domain. Figs. 13 and 14 show temperature and axial velocity profiles at several distances from the fuel nozzle.

Figure 11 depicts the effect of the boundary conditions on domain temperature. In case $\mathrm{C} 1$ the coflow properties are identical to the maximum temperature of the measured data as a consequence of limitation on the 2-D look-up table generated based on the classical FGM approach. This limitation forces to use aconstant compo- sition for reactants. In case $\mathrm{C} 1$ the coflow properties are identical to those at the minimum $\mathrm{O}_{2}$ and the maximum temperature of the measured data, duplicating the simulation of Abtahizadeh et al. [40]. In Fig. 13, it is depicted that the case C1 fails to reproduce the variation of oxidizer temperature at the boundary condition; therefore the temperature profile within the domain is not satisfactory.

The VIML method is implemented in the case C2. This method reproduces variation of ttemperature at the inlet boundary condition as it is clear in Fig. 13 for radial distance far from the nozzle tip where the reaction is not taking place. However, the flame is attached to the fuel nozzle. This incorrect prediction arises from the inappropriate look-up table generation using the classical expression for the progress variable. This is a common failure when building the progress variable focusing on autoignition phenomena. This is the result of the significant non-linearity of species mass fraction progress during the pre-ignition state leading to a non-monotonic progress variable. After the ignition and temperature rise, it is easier to build a monotonic progress variable. This difficulty roots the loss of the data in the table generation process specifically for the pre-ignition state. Consequently, it results in the incorrect prediction of autoignition delay time and lift-off height of the turbulent flame. As mentioned, despite the incorrect prediction of the near jet region, the look-up table error diminishes by 

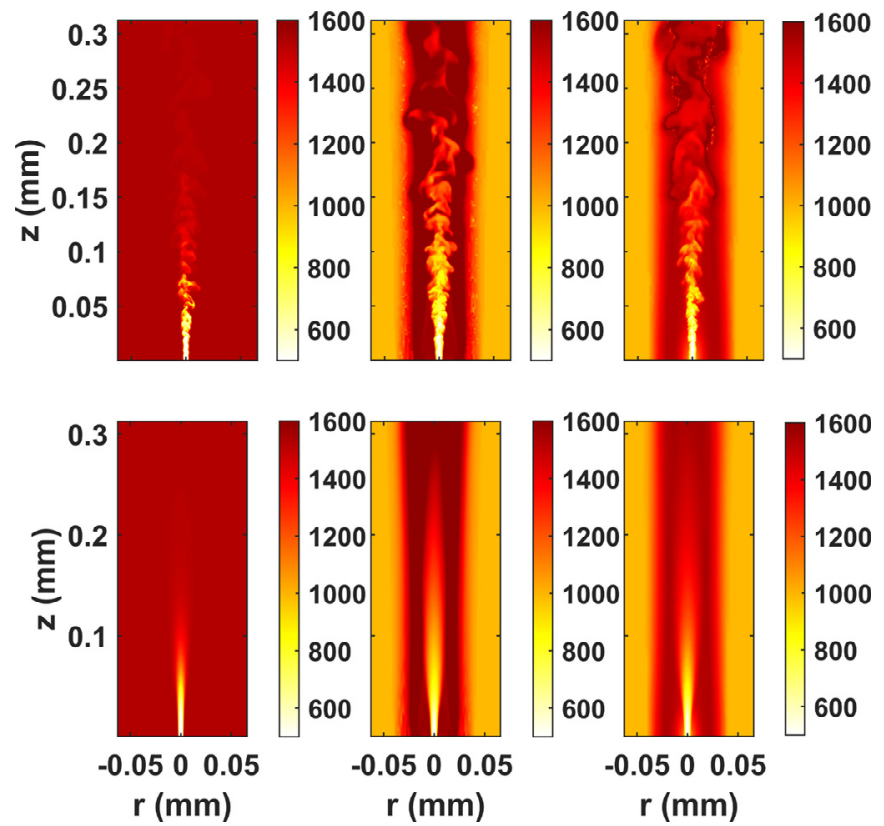

Fig. 11. Snapshot (top) and mean (bottom) of Temperature, of C1 (left), C2 (middle), C3 (right).

increasing the progress variable and for higher axial distance, the temperature error is lower as visible in, Fig. 13.

Both VIML and ACV-FGM methods are implemented in the case C3. Implementing the VIML method provides a 2-D look-up table for the varying composition inflow streams and the ACV-FGM method produces a bijective look-up table. The LES results show the appropriate prediction and satisfactory agreement with the experimental data. The temperature distribution at $Z=3 \mathrm{~mm}$ proof that the VIML accurately reproduced the variation of composition and temperature of coflow at the inlet boundary. Moreover, the

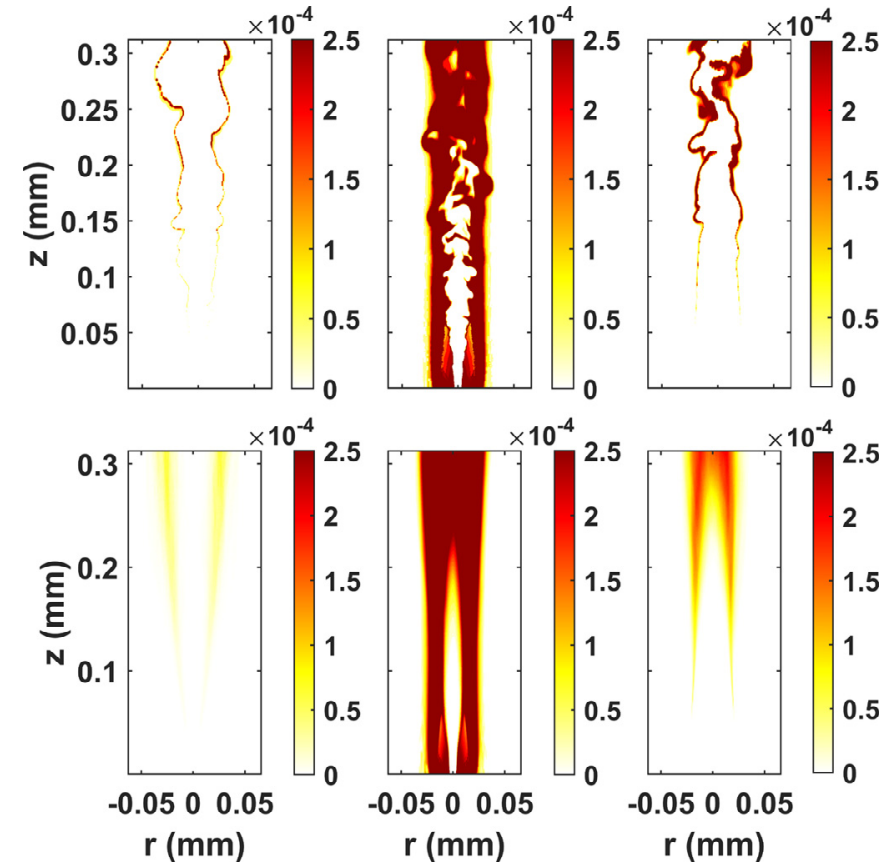

Fig. 12. Snapshot (top) and mean (bottom) of $\mathrm{OH}$ mass fraction, of $\mathrm{C} 1$ (left), $\mathrm{C} 2$ (middle), C3 (right).

ACV-FGM method precisely predicts the temperature as shown in Fig. 13. The new effort on the DJHC-I simulation using Diluted air FGM (DA-FGM) and Conditional Source Term Estimation (CSE) shows a noticeable improvement in the prediction of the temperature in comparison to the classical FGM model [45].

The $\mathrm{OH}$ profile can be interpreted as a flame position indicator. As shown in Fig. 12, the $\mathrm{Y}_{\mathrm{OH}}$ for case $\mathrm{C} 1$ is lower and the reaction

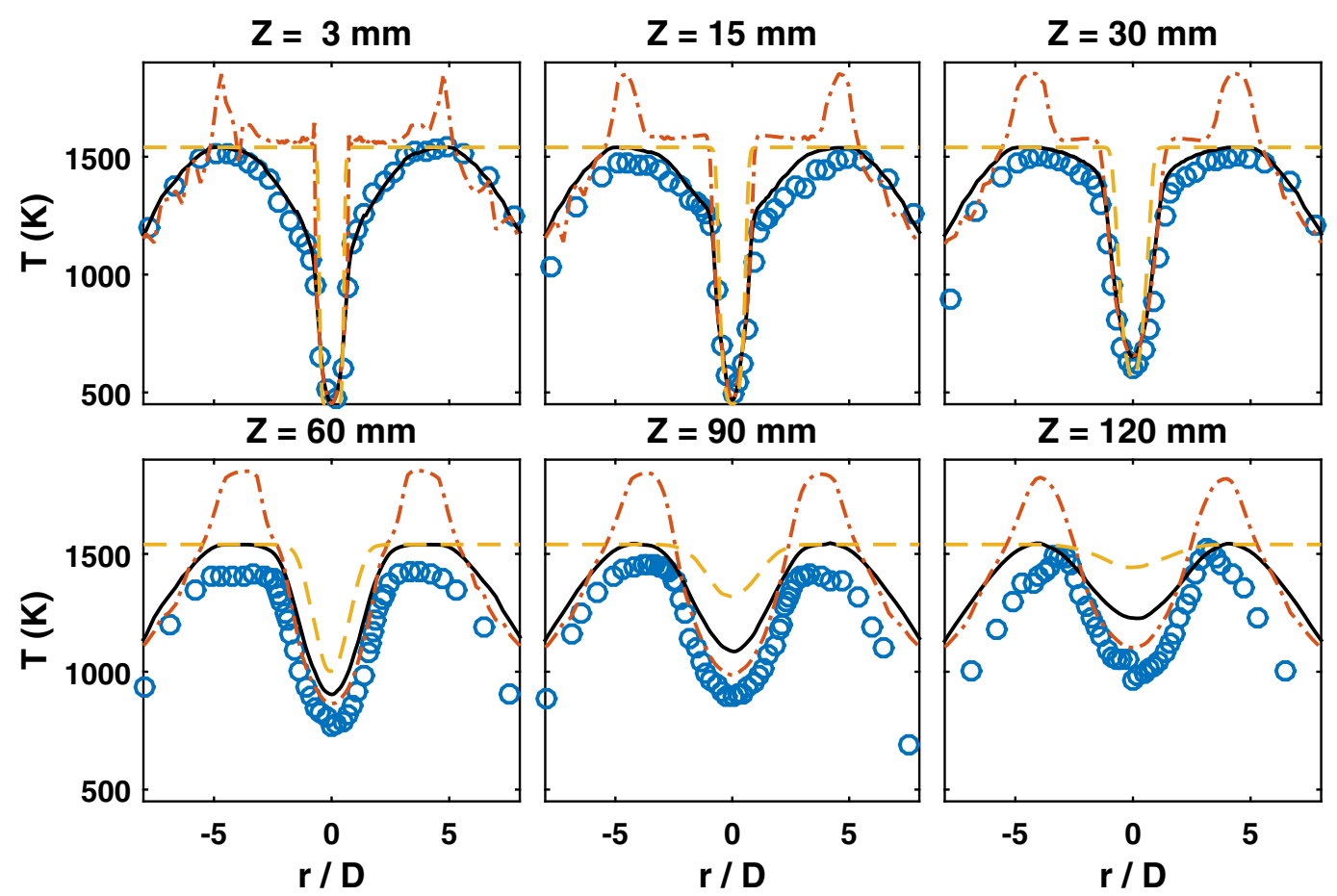

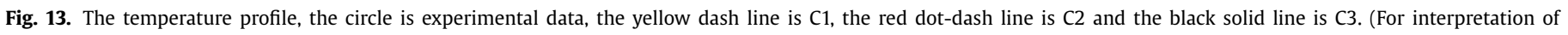
the references to color in this figure legend, the reader is referred to the web version of this article.) 

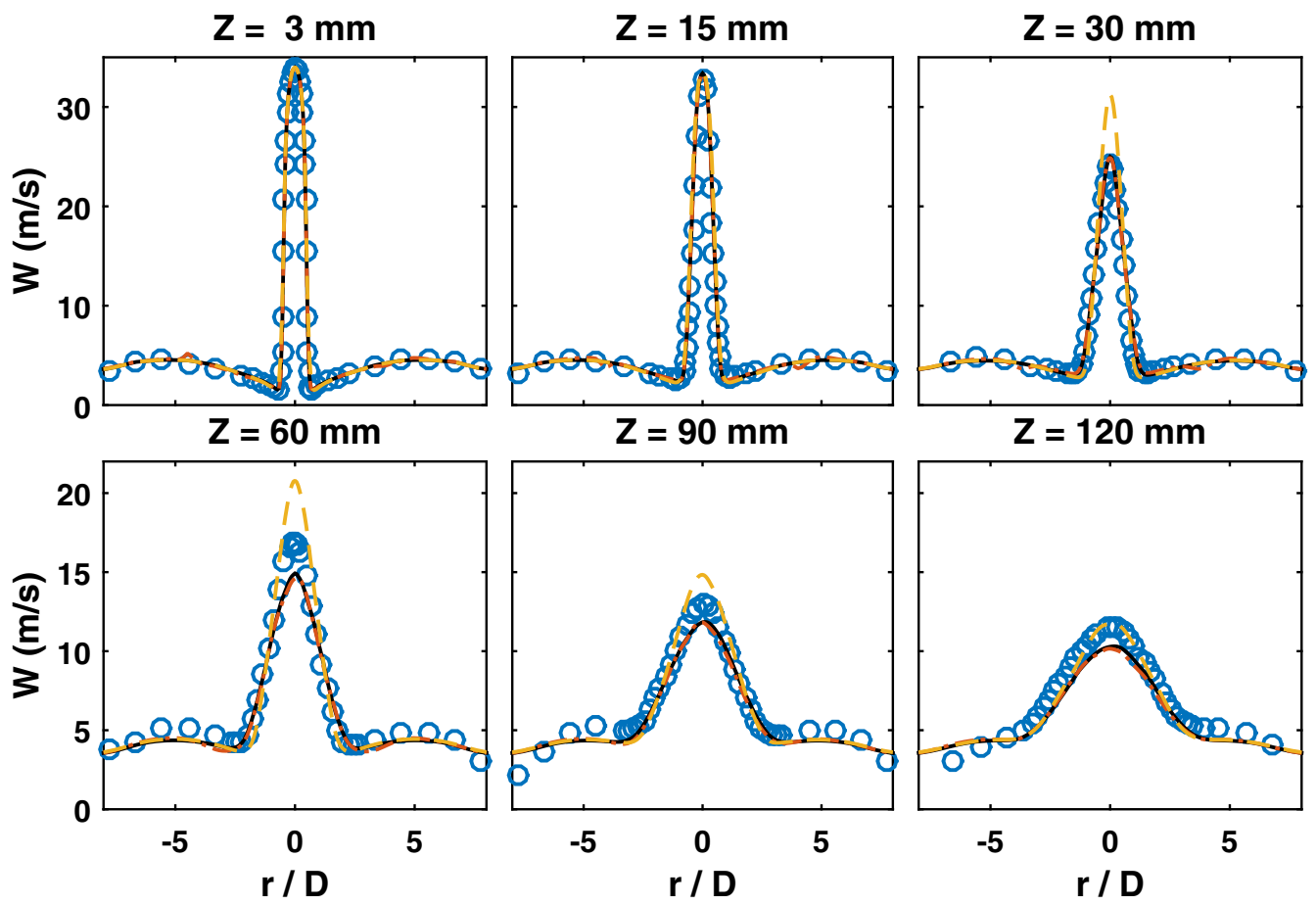

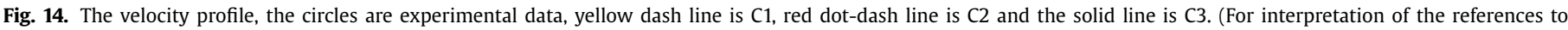
color in this figure legend, the reader is referred to the web version of this article.)
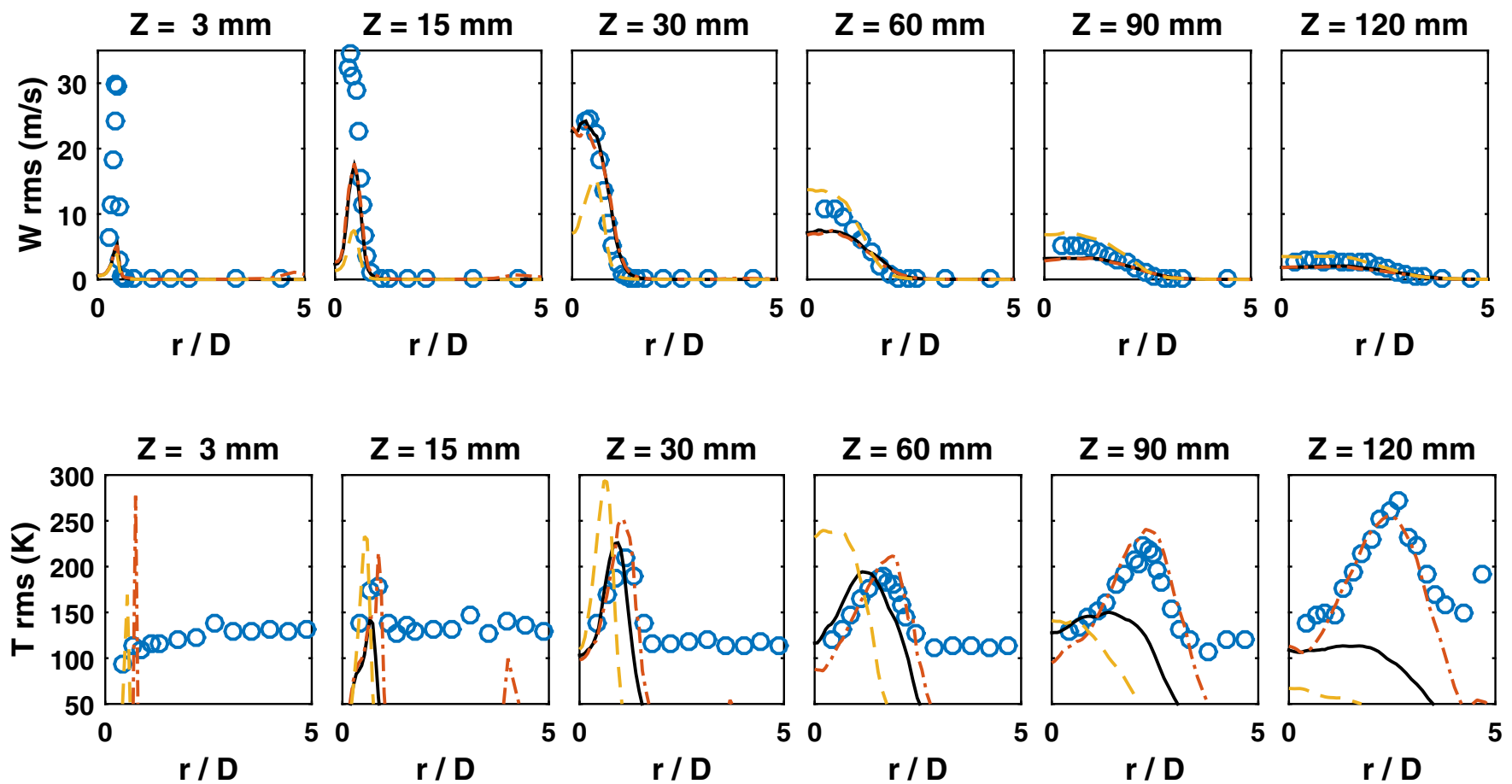

Fig. 15. The temperature and velocity RMS of the DJHC simulation results.

zone is narrower than case $\mathrm{C} 3$ which represents the lower reaction rate for case $\mathrm{C} 1$.

The $\mathrm{OH}$ species is used to find the lift-off height of the turbulent jet flame. Oldenhof et al. [38] used the $\mathrm{OH}$ chemiluminescence to detect the flame position and lift-off height. Their measurements showed the DJHC-I flame had a lift-off height of $\mathrm{Z}_{\mathrm{L}}=69 \mathrm{~mm}$. The lift-off height corresponds to $\mathrm{Y}_{\mathrm{OH}}=10^{-5}$ and it is about $\mathrm{Z}_{\mathrm{L}}=125 \mathrm{~mm}$ for case $\mathrm{C} 1$ which shows a large error regarding the experimental data. Lower $\mathrm{Y}_{\mathrm{O} 2}$ results in a slower re- action rate and higher lift-off height. While the lift-off height is $\mathrm{Z}_{\mathrm{L}}=67 \mathrm{~mm}$ for case $\mathrm{C} 3$ as shown in Fig. 12. This result implies that ACV-FGM is capable to predict accurately the lift-off height of the turbulent jet flame.

The temperature rise affects the velocity prediction within the computational domain. For Case C1, the temperature rise is over predicted at the jet center; therefore the velocity distribution is over predicted specifically at $Z=30 \mathrm{~mm}$ and $Z=60 \mathrm{~mm}$, Fig. 14. For the $\mathrm{C} 2$ and $\mathrm{C} 3$ the mean velocity prediction has 
good agreement with experimental data and these cases have the same velocity distribution despite the different progress variable definition. The RMS of the velocity and temperature are depicted in Fig. 15. The velocity RMS of three cases are fairly good but for the temperature RMS error increases along the radial direction.

\section{Conclusions}

Two novel methods are presented to modify the Flamelet generated manifolds focusing on the progress variable definition and the table generation procedure to generate a bijective 2-D look-up table.

A new mathematical definition of progress variable is introduced to make an inherently monotonic progress variable named Absolute Cumulative Variation (ACV) including the preferential diffusion effects. This method generates a bijective look-up table resulting in the precise prediction of the combustion properties such as ignition delay time, temperature rise, and species mass fraction like CO and NO.

The Variable Ignition Mixing Layer (VIML) is presented to handle multi-inflow streams or composition variations at the domain boundary condition. This method reduces the time and increases the accuracy of retrieving data from the look-up table by retaining a two-dimension table for complex inflow streams.

These methods are validated using the one-dimensional laminar flame model, as well as the large eddy simulation of Sandia piloted flames D, E, and F and the Delft Jet in Hot Coflow flame (DJHC-I).

The results of the 1-D laminar flame demonstrate that the ACVFGM method predicts the autoignition delay time and pollutants mass fraction accurately. This result confirms that the ACV method can successfully generate a bijective FGM look-up table.

The LES simulation of the Sandia flames is carried out to verify the VIML methods and the validity range of the fuel jet Reynolds number. This method correctly reproduces the temperature and chemical composition, such as CO and NO using a 2-D look-up table for the three-inflow stream. The increase of the fuel jet Reynolds number can slightly reduce the accuracy of mixture fraction prediction for some regions. Consequently, this error leads to inaccurate data retrieved from the look-up table. Nevertheless, the results still are in an acceptable range.

The Delft Jet in Hot Coflow flame (DJHC-I) is a lifted turbulent flame with a non-uniform oxidizer temperature and chemical composition at the coflow inlet domain boundary. The LES results indicate that the VIML method along with the ACV-FGM can accurately predict the temperature distribution as well as turbulent flame liftoff height with less than $5 \%$ error indicated by $\mathrm{OH}$ species.

As demonstrated, the proposed ACV-FGM model can be applied to partially premixed and non-premixed combustion applications and accurately predict the flame location, temperature distribution, and pollution emission. It diminishes the requirement for expert knowledge to define the most monotonic progress variable in an ad-hoc procedure and dramatically improves the description of this key parameter and reduces the preprocessing time. The VIML method can extend the potential of this method for combustion problems involving complex inflow streams.

\section{Declaration of Competing Interest}

None.

\section{Acknowledgments}

This work was partially completed during the first author's stay at the Eindhoven University of Technology as a visiting student and gratefully acknowledge generous support from the multiphase and reactive flows research group at the Eindhoven University of Technology.

\section{References}

[1] U. Maas, S.B. Pope, Simplifying chemical kinetics: intrinsic low-dimensional manifolds in composition space, Combust. Flame 88 (3) (1992) 239-264.

[2] A. Najafi-Yazdi, B. Cuenot, L. Mongeau, Systematic definition of progress variables and intrinsically low-dimensional, flamelet generated manifolds for chemistry tabulation, Combust. Flame 159 (3) (2012) 1197-1204.

[3] O. Gicquel, N. Darabiha, D. Thévenin, Liminar premixed hydrogen/air counterflow flame simulations using flame prolongation of ILDM with differential diffusion, Proc. Combust. Inst. 28 (2) (2000) 1901-1908.

[4] J. van Oijen, P. de Goey, Modelling of premixed laminar flames using Flameletgenerated manifolds, Combust. Sci. Technol. 161 (1) (Dec. 2000) 113-137.

[5] C.D. Pierce, P. Moin, Progress-variable approach for large-eddy simulation of non-premixed turbulent combustion, J. Fluid Mech. 504 (2004) 73-97.

[6] M. Ihme, C.M. Cha, H. Pitsch, Prediction of local extinction and re-ignition effects in non-premixed turbulent combustion using a flamelet/progress variable approach, Proc. Combust. Inst. 30 (1) (2005) 793-800.

[7] N. Peters, Laminar diffusion flamelet models in non-premixed turbulent combustion, Prog. Energy Combust. Sci. 10 (3) (1984) 319-339.

[8] N. Peters, Laminar flamelet concepts in turbulent combustion, Symp. Combust. 21 (1) (1988) 1231-1250.

[9] J.A. van Oijen, F.A. Lammers, L.P.H. de Goey, Modeling of complex premixed burner systems by using flamelet-generated manifolds, Combust. Flame 127 (3) (2001) 2124-2134.

[10] J.A. van Oijen, L.P.H. de Goey, Modelling of premixed counterflow flames using the flamelet-generated manifold method, Combust. Theory Model. 6 (3) (Sep. 2002) 463-478.

[11] B. Fiorina, O. Gicquel, L. Vervisch, S. Carpentier, N. Darabiha, Approximating the chemical structure of partially premixed and diffusion counterflow flames using FPI flamelet tabulation, Combust. Flame 140 (3) (2005) 147-160.

[12] B. Fiorina, O. Gicquel, L. Vervisch, S. Carpentier, N. Darabiha, Premixed turbulent combustion modeling using tabulated detailed chemistry and PDF, Proc. Combust. Inst. 30 (1) (2005) 867-874.

[13] M. Ihme, $H$. Pitsch, Prediction of extinction and reignition in nonpremixed turbulent flames using a flamelet/progress variable model: 1 . A priori study and presumed PDF closure, Combust. Flame 155 (1) (2008) 70-89.

[14] M. Ihme, H. Pitsch, Prediction of extinction and reignition in nonpremixed turbulent flames using a flamelet/progress variable model: 2. Application in LES of Sandia flames D and E, Combust. Flame 155 (1) (2008) 90-107.

[15] M. Ihme, Y.C. See, Prediction of autoignition in a lifted methane/air flame using an unsteady flamelet/progress variable model, Combust. Flame 157 (10) (2010) 1850-1862.

[16] P. Domingo, L. Vervisch, D. Veynante, Large-eddy simulation of a lifted methane jet flame in a vitiated coflow, Combust. Flame 152 (3) (2008) 415-432.

[17] E. Abtahizadeh, J. van Oijen, P. de Goey, Numerical study of Mild combustion with entrainment of burned gas into oxidizer and/or fuel streams, Combust. Flame 159 (6) (2012) 2155-2165.

[18] P. Wollny, B. Rogg, A. Kempf, Modelling heat loss effects in high temperature oxy-fuel flames with an efficient and robust non-premixed flamelet approach, Fuel 216 (2018) 44-52.

[19] H. Pitsch, M. Chen, N. Peters, Unsteady flamelet modeling of turbulent hydrogen-air diffusion flames, Symp. Combust. 27 (1) (1998) 1057-1064.

[20] H. Pitsch, Unsteady flamelet modeling of differential diffusion in turbulent jet diffusion flames, Combust. Flame 123 (3) (2000) 358-374.

[21] A. Sepman, E. Abtahizadeh, A. Mokhov, J. van Oijen, H. Levinsky, P. de Goey, Experimental and numerical studies of the effects of hydrogen addition on the structure of a laminar methane-nitrogen jet in hot coflow under Mild conditions, Int. J. Hydrog. Energy 38 (31) (2013) 13802-13811.

[22] K.K.J. Ranga Dinesh, X. Jiang, J.A. van Oijen, Direct numerical simulation of non-premixed syngas burning with detailed chemistry, Fuel 107 (2013) 343-355.

[23] K.K.J. Ranga Dinesh, J.A. van Oijen, K.H. Luo, X. Jiang, Near-field local flame extinction of oxy-syngas non-premixed jet flames: a DNS study, Fuel 130 (2014) 189-196.

[24] E. Abtahizadeh, P. de Goey, J. van Oijen, Development of a novel flamelet-based model to include preferential diffusion effects in autoignition of $\mathrm{CH} 4 / \mathrm{H} 2$ flames, Combust. Flame 162 (11) (2015) 4358-4369.

[25] M. Ihme, L. Shunn, J. Zhang, Regularization of reaction progress variable for application to flamelet-based combustion models, J. Comput. Phys. 231 (23) (2012) 7715-7721.

[26] T. Poinsot, D. Veynante, 2005 Edwards.

[27] Y.-S. Niu, L. Vervisch, P.D. Tao, An optimization-based approach to detailed chemistry tabulation: automated progress variable definition, Combust. Flame 160 (4) (2013) 776-785.

[28] M.U. Göktolga, J.A. van Oijen, L.P.H. de Goey, Modeling Mild combustion using a novel multistage FGM method, Proc. Combust. Inst. 36 (3) (2017) 4269-4277.

[29] A.W. Vreman, B.A. Albrecht, J.A. van Oijen, L.P.H. de Goey, R.J.M. Bastiaans, Premixed and nonpremixed generated manifolds in large-eddy simulation of Sandia flame D and F, Combust. Flame 153 (3) (2008) 394-416. 
[30] E. Oldenhof, M.J. Tummers, E.H. van Veen, D.J.E.M. Roekaerts, Transient response of the Delft jet-in-hot coflow flames, Combust. Flame 159 (2) (2012) 697-706.

[31] E. Oldenhof, M.J. Tummers, E.H. van Veen, D.J.E.M. Roekaerts, Role of entrainment in the stabilisation of jet-in-hot-coflow flames, Combust. Flame 158 (8) (2011) 1553-1563.

[32] R.W. Bilger, The structure of turbulent nonpremixed flames, Symp. Combust. 22 (1) (1989) 475-488.

[33] E. Abtahizadeh, A. Sepman, F. Hernández-Pérez, J. van Oijen, A. Mokhov, P. de Goey, H. Levinsky, Numerical and experimental investigations on the influence of preheating and dilution on transition of laminar coflow diffusion flames to Mild combustion regime, Combust. Flame 160 (11) (2013) 2359-2374.

[34] A.V. Sepman, S.E. Abtahizadeh, A.V. Mokhov, J.A. van Oijen, H.B. Levinsky, L.P.H. de Goey, Numerical and experimental studies of the no formation in laminar coflow diffusion flames on their transition to Mild combustion regime, Combust. Flame 160 (8) (2013) 1364-1372.

[35] M. Ihme, Y.C. See, LES flamelet modeling of a three-stream Mild combustor: analysis of flame sensitivity to scalar inflow conditions, Proc. Combust. Inst. 33 (1) (2011) 1309-1317.

[36] J. Lamouroux, M. Ihme, B. Fiorina, O. Gicquel, Tabulated chemistry approach for diluted combustion regimes with internal recirculation and heat losses, Combust. Flame 161 (8) (2014) 2120-2136.
[37] R.S. Barlow, J.H. Frank, Effects of turbulence on species mass fractions in methane/air jet flames, Symp. Combust. 27 (1) (1998) 1087-1095.

[38] E. Oldenhof, M.J. Tummers, E.H. van Veen, D.J.E.M. Roekaerts, Ignition kernel formation and lift-off behaviour of jet-in-hot-coflow flames, Combust. Flame 157 (6) (2010) 1167-1178.

[39] S.E. Abtahizadeh, Numerical study of mild combustion from laminar flames to large eddy simulation of turbulent flames with flamelet generated manifolds, Eindhoven University of Technology (2014).

[40] E. Abtahizadeh, P. de Goey, J. van Oijen, LES of Delft Jet-In-Hot Coflow burner to investigate the effect of preferential diffusion on autoignition of $\mathrm{CH}_{4} / \mathrm{H}_{2}$ flames, Fuel 191 (Supplement C) (2017) 36-45.

[41] M. Smooke, Reduced kinetic mechanisms and asymptotic approximations for methane-air flames, Lect. Notes Phys. 384 (1991).

[42] A. Vreman, R. Bastiaans, B. Geurts, A similarity subgrid model for premixed turbulent combustion, Flow Turb. Combust 82 (2009) 233-248.

[43] L.M.T. Somers, The Simulation of Flat Flames With Detailed and Reduced Chemical Models, Eindhoven University of Technology, 1994.

[44] L.D. Arteaga Mendez, M.J. Tummers, E.H. van Veen, D.J.E.M. Roekaerts, Effect of hydrogen addition on the structure of natural-gas jet-in-hot-coflow flames, Proc. Combust. Inst. 35 (3) (2015) 3557-3564.

[45] A.A.V Perpignan, A. Gangoli Rao, D.J.E.M. Roekaerts, Flameless combustion and its potential towards gas turbines, Prog. Energy Combust. Sci. 69 (2018) 28-62. 